NBER WORKING PAPER SERIES

\title{
MEDICAID MANAGED CARE AND INFANT HEALTH: A NATIONAL EVALUATION
}

\author{
Robert Kaestner \\ Lisa Dubay \\ Genevieve Kenney \\ Working Paper 8936 \\ http://www.nber.org/papers/w8936 \\ NATIONAL BUREAU OF ECONOMIC RESEARCH \\ 1050 Massachusetts Avenue \\ Cambridge, MA 02138 \\ May 2002
}

Support for this article was provided by the Robert Wood Johnson Foundation. The views expressed are those of the authors and should not be attributed to The Urban Institute, its trustees, or its funding partners. The authors gratefully acknowledge the helpful insights of Bo Garrett and Steve Zuckerman, seminar participants at the NBER Children's meeting April 4, 2002, and the programming assistance of Mary Lee. Emily Kurtz provided valuable editorial assistance. The views expressed herein are those of the authors and not necessarily those of the National Bureau of Economic Research.

(C) 2002 by Robert Kaestner, Lisa Dubay and Genevieve Kenney. All rights reserved. Short sections of text, not to exceed two paragraphs, may be quoted without explicit permission provided that full credit, including (C) notice, is given to the source. 
Medicaid Managed Care and Infant Health: A National Evaluation

Robert Kaestner, Lisa Dubay and Genevieve Kenney

NBER Working Paper No. 8936

May 2002

JEL No. I1

\begin{abstract}
In this study, we examine the effects of Medicaid managed care (MMC) on prenatal care utilization and infant health. We obtain separate estimates of the effect of primary care case management (PCCM) managed care programs and HMO managed care plans on prenatal care utilization, birth weight, and cesarean section. The results suggest the following: MMC was associated with a small, clinically unimportant decrease in the number of prenatal care visits; MMC had no statistically significant relationship to the APNCU index of the adequacy of prenatal care; MMC was associated with a significant increase in the incidence of low-birth weight and pre-term birth; and MMC had no association with the incidence of cesarean section. We argue that a causal interpretation of the first and third findings is unsupported by a careful reading of the evidence, and we conclude that Medicaid managed care had virtually no causal effect on, prenatal care use, birth outcomes, and cesarean section.
\end{abstract}

\author{
Robert Kaestner \\ Lisa Dubay \\ Genevieve Kenney \\ Institute of Government and Public Affairs \\ Urban Institute \\ Urban Institute \\ University of Illinois-Chicago \\ 815 West Van Buren Street, Suite 525 \\ Chicago, IL 60607-3525 \\ and NBER \\ kaestner@uic.edu
}




\section{Introduction:}

The number of Medicaid recipients who obtain their medical care through managed care organizations has greatly increased over the past ten years. The figures are well known: between 1991 and 2000, the proportion of Medicaid recipients in managed care rose from 10 to 56 percent (HCFA 2000). Moreover, all Medicaid eligibility groups, including the aged and disabled, have been affected, although low-income adults and children are somewhat over represented in Medicaid managed care. The potential consequences of such a change in the underlying financing and delivery of medical care to the Medicaid population have not gone unnoticed. There is widespread interest in assessing how the switch to Medicaid managed care has affected Medicaid recipients' access to medical care, their utilization of services, and the quality of medical care they receive. Ultimately, the switch to managed care may significantly affect the health of program participants, which is of vital public importance.

What factors caused the growth in Medicaid managed care? Cost was likely foremost: between 1980 and 1988, Medicaid enrollment was steady, and real expenditures were increasing at a six percent annual rate, which was similar to the rate of increase in all health care expenditures during this period (Cowan et al. 1999). Moreover, most of this annual increase in Medicaid expenditures was a result of the increased cost of care for the aged and disabled populations in the program, whereas the cost of care for low-income children and adults was relatively flat during this period. However, between 1989 and 1992, real expenditures for Medicaid increased at a dramatically greater rate than in the previous ten years and culminated in a 26 percent increase between 1991 and 1992 (HCFA 2000). The large increases in expenditures during this period were driven primarily by three factors: growth in Disproportionate Share Program (DSH); growth in the enrollment of low-income children and adults, following expansions in eligibility; and by the continued increase in the cost of care for the aged and disabled. In response to these growing expenditures, states turned toward managed care, which during the same period was beginning to have considerable success controlling costs in the private sector (Cowan et al. 1999). Consequently, between 1993 and 1996, the share of Medicaid beneficiaries in managed care increased from 14 to 40 percent (HCFA 2000). Notably, as the proportion of Medicaid recipients in managed care 
increased during this period, the growth rate in Medicaid expenditures slowed, reaching a low of zero between 1995 and 1996 (HCFA 2000), but much of this decline is accounted for by the cap on DSH payments. Since 1996, growth in Medicaid expenditures has continued to be moderate by historical standards.

Another factor motivating the move to Medicaid managed care was the longstanding concern that Medicaid patients lacked access to quality primary care. Medicaid's relatively low reimbursement rates, partly a response to fiscal pressure, and its requirement that physicians accept the government's reimbursement as payment in full, limited physician participation. As a result, many Medicaid recipients often lacked a usual source of care (Newacheck et al. 1996; Newacheck et al. 1998). Medicaid managed care was viewed as a way to address this problem. Primary care case management, which links a Medicaid recipient with a primary care physician who is typically paid a monthly fee for coordinating patient care, should expand access to primary care. The structure of health maintenance organizations (HMOs), which is typified by a gatekeeper and a closed provider network, combined with appropriate financial incentives (e.g., capitated payments), could theoretically lead to greater access to primary care, more coordinated care, and an increase in preventive care. In sum, Medicaid managed care was viewed as a way to reduce costs and increase access to care and the quality of services received.

Various observers have noted the potential risks associated with the switch to Medicaid managed care. Probably the greatest of these is that providers may respond inappropriately to the financial incentives (e.g., capitation) inherent many managed care organizations, thereby limiting use of medical care, and consequently adversely affecting the health of Medicaid recipients. Another risk is that traditional safety-net providers, who have considerable expertise caring for low-income populations, will be excluded from managed care networks, forcing patients to interrupt established provider relationships as their eligibility and participation in Medicaid change. Again, this possibility may adversely affect the health of Medicaid recipients.

Given that approximately 40 percent of all births are now covered by Medicaid, understanding the effects of managed care generally and of different approaches to managed care for women covered by 
Medicaid is critical. Surprisingly, despite Medicaid's growing reliance on managed care, there is a relative paucity of empirical research on the subject. In particular, the effects of Medicaid managed care on health and how it affected children are two areas where empirical research is particularly scant. Importantly, Medicaid programs historically have been thought to provide poorer access relative to private insurance coverage thus new approaches, such as managed care, may have been implemented prior to a comprehensive assessment of it impact.

The purpose of this study is to examine the effects of Medicaid managed care on prenatal care utilization and infant health. Our analysis of infant health is particularly germane given the relative scarcity of such research and the heightened public concern with this particular issue. Indeed, poor infant health among low-income families was arguably the most substantive motivating factor behind the expansion of Medicaid eligibility for pregnant women occurring in the late 1980s. A second contribution of our analysis is that we differentiate between types of managed care models. Specifically, we obtain separate estimates of the effect of primary care case management (PCCM) managed care programs, which are usually not capitated, and HMO managed care plans, which are usually fully capitated, on prenatal care utilization and low birth weight. We also differentiate between managed care plans that mandate participation and those for which participation is voluntary. These distinctions are important because of differences in the financial incentives and organizational structure associated with the two types of managed care organizations, and because of selection issues associated with non-random participation. Much previous research assessing the effect of Medicaid managed care was conducted during a period where PCCM was the dominant mode of managed care; but increasingly, the typical Medicaid managed care organization has been an HMO that bears most of the financial risk of providing care.

\section{Previous Research:}

There have been a number of studies on the effects of Medicaid managed care, and most are concerned with access to care and use of services. A few studies examined participant satisfaction with managed care and even fewer examined the effect of Medicaid managed care on health. In this review, 
we focus on those studies investigating the effect of Medicaid managed care on utilization and health. This concentration is appropriate because ultimately it is a person's health and the cost of achieving that health that matters most for health policy, and thus Medicaid managed care should be judged on the basis of its effect—relative to traditional Medicaid—on health. However, because health is often difficult to measure, utilization may also have some efficacy as a criterion to measure the effectiveness of Medicaid managed care, although the link between utilization and health is generally weak (Newhouse 1993, Friedman 2000).

An early summary of the effects of Medicaid managed care on utilization is provided by Hurley et al. (1993). They review findings from 25 evaluations of Medicaid managed care programs that differ along several dimensions including the voluntary nature of program participation and the financing method (e.g., capitation). Emphasis, however, is placed on the findings from 12 evaluations that had more "reliable and valid assessments." Of these 12 programs, five had a fee-for-service payment structure and seven had capitated payments. The results from these 12 studies reveal that relative to traditional Medicaid, Medicaid managed care was associated with no change in physician visits and a decrease in the following: emergency room use, use of ancillary services (e.g., x-rays), prescription drug use and inpatient use. Hurley et al. (1993) also evaluate whether or not the effects of managed care depend on the way providers were reimbursed. Interestingly, the only significant difference revealed by this comparison relates to physician visits; managed care plans reimbursed on a fee-for-service basis were more likely to show an increase in physician visits. Otherwise, the effects of Medicaid managed care did not differ with respect to method of payment.

The finding that Medicaid managed care reduced utilization, particularly inpatient and emergency department use, has not consistently been confirmed in later studies. Indeed, a reanalysis of the Minnesota Medicaid Demonstration project by Freund et al. (1996) revealed no difference in utilization of medical services between recipients in a capitated managed care program and those in fee-for-service Medicaid. Similar results were reported by Sisk et al. (1996) who found no differences in utilization between traditional Medicaid and Medicaid managed care beneficiaries in New York. In contrast, a 
recent study by Zuckerman and Brennan (2001), which used a nationally representative sample, found that participation in an HMO Medicaid managed care program reduced emergency room use and increased health care utilization relative to fee-for-service Medicaid. Zuckerman and Brennan (2001) also report, however, that participation in a primary care case management program had no effect on Medicaid recipients' utilization. Finally, Garrett et al. (2001) report similarly mixed findings in their analysis of a nationally representative sample. Most of these studies used samples of adults and focused on managed care plans that were reimbursed on a capitated basis.

Inconsistent findings also characterize the literature concerned specifically with the effect of Medicaid managed care on children. Mauldon et al. (1994), Holhen et al. (1990) and Long and Coughlin (2001) all report similar findings for children in capitated managed care plans. In the Mauldon et al. (1994) study, children in Medicaid managed care were equally likely to receive a checkup and to use the emergency room, but less likely to have an acute care visit than were children in fee-for-service Medicaid. Holhen et al. (1990) reported no differences in the number of physician visits between children in Medicaid managed care and traditional fee-for-service Medicaid in Suffolk County, New York. And Long and Coughlin (2001), who examined the effect of Medicaid managed care in rural Minnesota, “...find few significant differences in access to, use of, and satisfaction with health care services for children under MMC relative to FFS"(p. 20). In contrast, a study by Gavin et al. (1998) of the effect of Medicaid managed care on children's use of medical services in Florida showed declines in emergency department use similar to those reported in earlier studies. ${ }^{1}$ Similarly, Zuckerman and Brennan (2001) and Garrett et al. (2001) found that among two nationally representative samples of children, those in Medicaid HMOs use the emergency room less and have greater health care utilization, especially preventive care, than do those in fee-for-service Medicaid. Gavin et al. (1998) also study the effects of Medicaid managed care in New Mexico, and in this case, the results indicated that there were no statistically significant differences in utilization between children in Medicaid managed care and those in

\footnotetext{
${ }^{1}$ Somewhat surprisingly, however, the same study found that ambulatory care visits and preventive (EPSDT) visits increased under Medicaid managed care in Florida.
} 
traditional Medicaid. Both the Florida and New Mexico programs were fee-for-service managed care. Finally, Gadomski et al. (1998) report that children in a fee-for-service Medicaid managed care plan in Maryland had greater utilization, including emergency department use, than did children in the traditional Medicaid program.

Several studies examined the effect of Medicaid managed care on pregnant women and infants in a single state. The earliest was by Krieger et al. (1992) who investigated the effect of Medicaid managed care in Washington State. Three separate managed care organizations were involved in the study and each was paid on a capitated basis. Overall, Krieger et al. (1992) report no systematic effect of Medicaid managed care on prenatal care or birth weight. However, an anomalous finding from this analysis that undermines its credibility is that the Medicaid managed care plan associated with a significant worsening of prenatal care utilization was also associated with a significant improvement in birth outcomes. Levinson and Ullman (1998) report on a similar analysis of prenatal care and birth weight from Wisconsin, which had a Medicaid managed care program that relied on capitated payments. The results of this analysis indicated that Medicaid managed care was associated with an increase in prenatal care utilization, but no difference in birth weight, as compared to traditional fee-for-service Medicaid. Griffin et al. (1999) evaluated the effect of Medicaid managed care on prenatal care utilization in Rhode Island, which had a statewide, mandatory managed care program that used capitated payments to reimburse providers. Results indicated that the switch to Medicaid managed care was associated with a significant increase in prenatal care utilization. A similar increase was not observed for privately-insured patients in Rhode Island during this period. Thus, the authors concluded that Medicaid managed care increased prenatal care utilization, but noted that the increase was likely due to a variety of factors including an increase in reimbursement rates for providers. Finally, Moreno (1999) examined differences in perinatal outcomes (e.g., prenatal care and low birth weight) in Tennessee before and after the implementation of Medicaid managed care in 1994. The authors report that no statistically significant pre-post differences in outcomes were found. 
This brief review of the extant empirical research yields several insights. First, the empirical literature has not reached a consensus as to the effect—relative to traditional Medicaid—of Medicaid managed care on health care utilization. One possible explanation of this non-uniformity of results is because virtually all of the evaluations reviewed were based on non-experimental research designs. The key problem with this research strategy is finding the appropriate counterfactual outcome to compare to outcomes in Medicaid managed care. In fact, some studies did not even use a comparison group (e.g., Moreno 1999) and many used regression analysis to adjust for observable differences, but ignored potentially important unobservable differences (e.g., Mauldon et al. 1994; Zuckerman and Brennan 2001). If we limit the review to what may arguably be considered the most well-designed studies, there is more consistency in the findings, but some non-uniformity remains. For example, studies reviewed by Freund et al. (1989) and those by Long and Coughlin (2001) and Gavin et al. (1998) all use the same methodology - a difference-in-difference research design where pre-post differences of a treatment group are compared to the pre-post differences of a comparison group. These studies reach the same conclusion only for certain outcomes, namely that Medicaid managed care reduces emergency department use. For other outcomes, the studies reach differing conclusions. In addition, a similarly designed study by Godomski et al. (1998) found that Medicaid managed care increased many types of utilization including emergency department care. Financing differences among managed care programs cannot explain this inconsistency since the Godomski et al. (1998) study and the Gavin et al. (1998) study both focused on a fee-for-service managed care program.

A second notable aspect of the existing empirical literature is its focus on single-state studies. In fact, there are only two national studies and neither examined the effect of Medicaid managed care on infant health. Evaluations of the effects of Medicaid managed care have come primarily from small demonstration projects implemented in the 1980s and early 1990s. The relatively small sample sizes in most of these studies raises questions as to their statistical power. Moreover, the absence of an evaluation based on a broader geographic sample limits the usefulness of the existing literature for policymakers. It 
is appropriate to question the applicability of these early state studies to other states and other time periods. A national study covering a more recent period can address some of these concerns.

Third, there are very few studies of the effect—relative to traditional Medicaid—of Medicaid managed care on health. Studies of infant health provide the exception, although two of the studies reviewed above examined the effect of Medicaid managed care on avoidable hospitalizations, which are a good proxy of health status. Again, there is no consistent finding. Studies of infant health indicated that Medicaid managed care had no effect on birth weight even though it was often associated with an increase in prenatal care utilization (Krieger et al. 1992; Levinson and Ullman 1998). In contrast, Medicaid managed care was associated with a decrease in avoidable hospitalizations among children and an increase in preventive care (Gavin et al. 1998; Godomski et al. 1998).

There are virtually no other studies of the effect of Medicaid managed care on health. However, there have been limited attempts to assess the effect of Medicaid managed care on the quality of care and satisfaction with care, but the relationship of these measures to health is not well documented. As noted above, health is arguably the litmus test for evaluating the effectiveness of Medicaid managed care. Patient satisfaction and measures of the quality care are not adequate proxies for health and cannot replace health status as the critical outcome for evaluating Medicaid managed care. Moreover, there is little existing evidence as to the effect of Medicaid managed care on the quality of care and patient satisfaction, particularly for children (Sisk et al. 1996; Bergman and Homer 1998; Szilalgyi 1998).

In sum, the switch to Medicaid managed care has occurred in the absence of definitive empirical information related to the effect of Medicaid managed care on health care utilization and health. The desire to contain costs and the belief that managed care is the way to accomplish this goal without adverse consequences has led policymakers to adopt Medicaid managed care. Of course, managed care in the public sector was preceded by managed care in the private sector. In 1992, just before the rapid growth in Medicaid managed care, nearly 70 percent of all privately insured persons were in some type of managed care. The experience of the private sector undoubtedly influenced the public sector. However, while there is considerable evidence that managed care has reduced costs in the private sector, there is relatively 
little evidence of its effect on health (Miller and Luft 1997; Glied 2000). Thus, an important criterion for evaluating the switch to Medicaid managed care should be its affect on the health of low-income populations.

In this paper, we address this issue. We present the first national evaluation of the effect of Medicaid managed care on prenatal care and infant health. Our analysis covers the period from 1990 to 1996, a period of rapid growth in Medicaid managed care, and we obtain estimates of the effect of different forms of managed care organizations (PCCM vs. HMO). Finally, our analysis pays particular attention to the statistical problems associated with non-experimental evaluations. We use a pre-post research design with comparison group that is based on within-county, time variation in Medicaid managed care programs.

\section{Empirical Model and Statistical Methodology:}

The hypothesis underlying our empirical analysis is straightforward: the change in the financing and organization of the provision of care that Medicaid managed care represents may affect the quantity and quality of care, which may in turn affect health. Accordingly, the goal of the analysis is to obtain causal estimates of the effect of Medicaid managed care on prenatal care utilization and infant health, as measured by birth weight.

Our empirical model is guided by economic theory, specifically, the economic model of the demand for health and health care utilization. In this model, infant health is produced by the family using several health inputs, which broadly speaking consist of medical care (e.g., prenatal care), other market goods (e.g., maternal nutrition and exercise), and parental time. Infant health also depends on biological determinants of health that are unaffected by family actions, and the technical relationship governing the transformation of health inputs (e.g., maternal nutrition) into infant health. In addition, families have limited resources (i.e., money and time) and must make choices on how to allocate these scarce resources to various uses including the production of infant health. 
This model yields what economists refer to as the demand functions for infant health and health inputs. These demand functions describe the factors that account for variations in infant health and prenatal care utilization. In general, demand functions for infant health and prenatal care utilization depend on prices of health care inputs (e.g., prenatal care), prices of market goods (i.e., inputs) used to produce infant health, family income, family preferences for child quality, and factors that affect the technical transformation of health inputs into infant health.

A simple algebraic representation of the demand function for infant health is as follows:

$$
\mathrm{LBW}_{\mathrm{ijt}}=\beta_{0}\left(\mathrm{NM}_{\mathrm{ijt}}\right)+\beta_{1}\left(\mathrm{M}_{-} \mathrm{FFS}_{\mathrm{ijt}}\right)+\beta_{2}\left(\mathrm{M}_{-} \mathrm{HMO}_{\mathrm{ijt}}\right)+\mathrm{X}_{\mathrm{ijt}} \lambda+\phi_{\mathrm{j}}+\tau_{\mathrm{t}}+\left(\delta_{\mathrm{k}} \mathrm{x} \tau_{\mathrm{t}}\right)+v_{\mathrm{ijt}}
$$

(1) $\mathrm{i}=1, \ldots, \mathrm{N}$ (individuals)

$\mathrm{j}=1, \ldots, \mathrm{M}$ (counties)

$\mathrm{k}=1, \ldots, 50$ (states)

$\mathrm{t}=1990, \ldots, 1996$

In equation (1), $L B W_{i j t}$ is equal to one if a birth was below 2500 grams, which is an important measure of infant health; $\mathrm{NM}_{\mathrm{ijt}}$ is equal to one if a mother is not covered by Medicaid, $\mathrm{M}_{-} \mathrm{FFS}_{\mathrm{ijt}}$ is equal to one if a mother is covered by Medicaid fee-for-service; $\mathrm{M}_{-} \mathrm{HMO}_{\mathrm{ijt}}$ is equal to one if a mother is covered by a Medicaid managed care plan (either PCCM or HMO); $X_{i j t}$ is a vector of personal attributes of the mother such as age, race/ethnicity, education, marital status and maternal health, all of which may be viewed as exogenous determinants of family preferences for child health, family income, the price of other prenatal care inputs (e.g., mother's time) and the health production technology; $\phi_{j}$ is a county fixed effect; $\tau_{t}$ is a year fixed effect; and $\left(\delta_{\mathrm{k}} \mathrm{x} \tau_{\mathrm{t}}\right)$ are state-specific time trends. ${ }^{2}$ The parameters of equation (1) can be estimated using ordinary least squares regression methods using individual level data from birth certificates. ${ }^{3}$

\footnotetext{
${ }^{2}$ A similar model can be written for prenatal care utilization.

${ }^{3}$ The use of ordinary least squares (OLS) is appropriate even for dichotomous dependent variables. In such cases, the advantage of OLS is that it does not require the researcher to choose a possibly incorrect probability distribution for the error term such as that required by logisitc or Probit regression. The disadvantage is that the standard errors
} 
In practice, we cannot estimate equation (1) because birth certificates do not have information on insurance status or participation in managed care. The only information we have is from an Urban Institute survey that indicates whether or not a county has a Medicaid managed care plan of a specific type —-for example, an HMO with mandatory participation—at time (t). This will result in biased estimates of the effect of interest: $\beta_{2}-\beta_{1}$. The model we estimate is the following:

$\mathrm{LBW}_{\mathrm{ijt}}=\alpha_{0}+\alpha_{1}\left(\mathrm{CNTY}_{-} \mathrm{HMO}_{\mathrm{jt}}\right)+\mathrm{X}_{\mathrm{ijt}} \lambda+\phi_{\mathrm{j}}+\tau_{\mathrm{t}}+\left(\delta_{\mathrm{k}} \mathrm{x} \tau_{\mathrm{t}}\right)+v_{\mathrm{ijt}}$

(2) $\mathrm{i}=1, \ldots, \mathrm{N}$ (individuals)

$\mathrm{j}=1, \ldots, \mathrm{M} \quad$ (counties)

$\mathrm{k}=1, \ldots, \mathrm{K} \quad$ (states)

$\mathrm{t}=1990, \ldots, 1996$

where $\mathrm{CNTY}_{-} \mathrm{HMO}_{\mathrm{jt}}$ is an indicator of whether or not county $\mathrm{j}$ at time $\mathrm{t}$ has a managed care program. The parameter $\alpha_{1}$ measures the following:

(3) $\mathrm{E}\left(\mathrm{LBW} \mid \mathrm{CNTY}{ }_{-} \mathrm{HMO}_{\mathrm{jt}}=1\right)-\mathrm{E}\left(\mathrm{LBW} \mid \mathrm{CNTY}_{-} \mathrm{HMO}_{\mathrm{jt}}=0\right)$

and the bias can be derived as follows:

$\mathrm{E}\left(\mathrm{LBW} \mid \mathrm{CNTY}-\mathrm{HMO}_{\mathrm{jt}}=1\right)=\beta_{2} \mathrm{E}(\mathrm{M}) \mathrm{E}(\mathrm{P})+\beta_{1} \mathrm{E}(\mathrm{M})[1-\mathrm{E}(\mathrm{P})]+\beta_{0}[1-\mathrm{E}(\mathrm{M})]$

(4) where

$\mathrm{M}=1$ if person is enrolled in Medicaid

$\mathrm{P}=1$ if person is enrolled in Medicaid and in a managed care plan

and

(5) $\mathrm{E}\left(\mathrm{LBW} \mid \mathrm{CNTY}-\mathrm{HMO}_{\mathrm{jt}}=0\right)=\beta_{1} \mathrm{E}(\mathrm{M})+\beta_{0}[1-\mathrm{E}(\mathrm{M})]$

SO

(6) $\mathrm{E}\left(\mathrm{LBW} \mid \mathrm{HMO}_{\mathrm{jt}}=1\right)-\mathrm{E}\left(\mathrm{Y} \mid \mathrm{HMO}_{\mathrm{jt}}=0\right)=\left(\beta_{2}-\beta_{1}\right) \mathrm{E}(\mathrm{M}) \mathrm{E}(\mathrm{P})$

As equation (6) indicates, the estimated effect will be biased toward zero and the magnitude of the bias depends on the proportion of women covered by Medicaid $[\mathrm{E}(\mathrm{M})]$ and enrolled in managed care $[\mathrm{E}(\mathrm{P})]$.

If the $\mathrm{E}(\mathrm{M})$ and $\mathrm{E}(\mathrm{P})$ are close to one, than the bias will be small.

of the estimates are biased because of heteroscedasticy. This problem is mediated by the large number of observations used in the analysis. 
To minimize the bias, we use demographic characteristics to identify women most likely to be eligible for, and covered by, Medicaid. Specifically, we use education and marital status to select women most likely to be eligible for and participating in Medicaid. For example, according to data from the 1992 Current Population Survey, nearly all unmarried pregnant women with fewer than 12 years of education are eligible for Medicaid. Moreover, 85.2 percent of this group of women reported having Medicaid coverage (see Table 3 below). In contrast, few married women with 12 to 15 years of education are eligible for Medicaid and Medicaid covers only 12.6 percent of them (see Table 3 below). Thus, by limiting the sample to women with certain demographic characteristics, we are confident that we have identified an appropriate sample of women to examine the effects of Medicaid managed care. This approach has been used previously by Dubay, Kaestner and Waidman $(1999,2001)$ and Dubay, Joyce, Kaestner, and Kenney (2001).

To further minimize the bias, we can make use of information as to whether or not the managed care plan was voluntary or mandated. Mandated plans will be associated with high proportions of women in the managed care plan $[\mathrm{E}(\mathrm{P})$ is close to one]. So focusing on counties with managed care plans with mandatory participation addresses the bias from not knowing who is enrolled in managed care. ${ }^{4}$

Given the above data setup, the parameters of equation (2) can be estimated using a variety of statistical procedures (e.g., ordinary least squares). However, there are two problems that undermine the causal interpretation of such estimates. The first is that some Medicaid managed care programs were voluntary. The voluntary nature of these programs makes it likely that participation is not randomly determined. For example, there is some evidence suggesting that pregnant women who choose to be in Medicaid managed care may be healthier or have lower rates of utilization than women in the traditional Medicaid program (Sisk et al. 1996; Leibowitz et al. 1992; West et al. 1996). In the absence of data on these differences, estimates of the effect of Medicaid managed care will be biased by this selection process. To address this issue, we estimate a modified version of equation (2) that differentiates between

\footnotetext{
${ }^{4}$ While we estimate effects for both voluntary and mandatory arrangement, we focus our results on mandatory programs for this reason.
} 
voluntary and mandated managed care programs. Medicaid managed care programs that mandate participation will be less affected by the non-random selection bias than voluntary programs. The modified empirical model is:

$$
\begin{aligned}
& \mathrm{LBW}_{\mathrm{ijt}}=\alpha_{0}+\alpha_{1}\left(\mathrm{M}_{-} \mathrm{HMO}_{\mathrm{jt}}\right)+\alpha_{2}\left(\mathrm{~V}_{-} \mathrm{HMO}_{\mathrm{jt}}\right)+\mathrm{X}_{\mathrm{ijt}} \lambda+\phi_{\mathrm{j}}+\tau_{\mathrm{t}}+\left(\delta_{\mathrm{k}} \mathrm{x} \tau_{\mathrm{t}}\right)+v_{\mathrm{ijt}} \\
& (7) \mathrm{i}=1, \ldots, \mathrm{N} \quad \text { (individuals) } \\
& \mathrm{j}=1, \ldots, \mathrm{M} \quad \text { (counties) } \\
& \mathrm{k}=1, \ldots, \mathrm{K} \quad \text { (states) } \\
& \mathrm{t}=1990, \ldots, 1996
\end{aligned}
$$

Equation (7) is identical to equation (2) except that the effects of managed care programs are allowed to differ according to whether or not they are voluntary (V) or mandatory (M) programs. A comparison of the estimated effects between voluntary and mandated programs can provide insight into the seriousness of the selection issue. Estimates associated with the mandatory programs are more credible indicators of managed care effects because they are not affected by non-random selection into the program and because they minimize the bias associated with not knowing who is enrolled in managed care.

A second statistical issue concerns the validity of the pre-post design underlying equations (2) and (7). Both equations include county controls $\left(\phi_{j}\right)$, which account for unmeasured, time-invariant factors specific to the county that affect birth weight and prenatal care utilization, and controls for statetime (trend) effects $\left(\delta_{\mathrm{k}} \times \tau_{\mathrm{t}}\right)$. Therefore, identification of the effects of Medicaid managed care is coming from the pre-post differences in outcomes within a county, conditional on state-specific trends. Nevertheless, there may be unmeasured, time-varying factors specific to the counties that affect birth weight and prenatal care utilization, and which are correlated with the switch to Medicaid managed care. This circumstance would result in biased estimates of the effect of Medicaid managed care. ${ }^{5}$

To bolster the causal interpretation of the findings from our analysis, we stratify the sample by the likelihood of being eligible for, and covered by, Medicaid. As noted above, education and marital 
status are reasonably good proxy variables for Medicaid eligibility and coverage. Therefore, we can estimate equation (7) for groups of women who differ by their likelihood of being covered by Medicaid and therefore affected by Medicaid managed care. There should be a clear pattern to the results; estimated effects of Medicaid managed care should be larger for groups most likely affected. In contrast, similar estimates across groups that differ in their likelihood of being affected by Medicaid managed care is evidence that there is some unmeasured, time-varying factor that affects prenatal care utilization and birth weight, which is also correlated with the implementation of Medicaid managed care. While not explicit, this approach uses groups less likely to be affected by Medicaid managed care as a comparison group. Pre-post changes in prenatal care and birth weight associated with the introduction of Medicaid managed care should be larger for the treatment group, the group most likely affected by Medicaid managed care, than for the comparison group, the group least likely affected.

Finally, it is important to acknowledge that we are assessing the impact of state policy choicesmandatory and voluntary managed care programs as they are implemented in practice—not managed care per se. Accordingly, we interpret our estimates as the average national effects of the managed care policy choices states have made in a given county.

\section{Data:}

The principal source of data for this analysis is the National Natality Files for 1990 through 1996. These files contain information on all births in the United States collected from birth certificates, but because of missing information on education and marital status, we cannot use observations from upstate New York. The Natality Files contain information on prenatal care use, birth weight, delivery method, and information on maternal characteristics including age, race, education, marital status, medical risk factors and reproductive history. We use only observations for singleton births.

\footnotetext{
${ }^{5}$ One way to address this issue is to include controls for county-specific trends. A drawback of this strategy is that it overly taxes the data by requiring the estimation of approximately an additional three thousand (the number of counties) parameters.
} 
As noted earlier, use of the National Natality files yields extremely large samples of births. This is important because estimates of the effect of Medicaid managed care are expected to biased toward zero by measurement error. Thus, the large sample sizes will allow us to detect reliably very small effects. Moreover, given the large sample sizes, we are able to examine the effect of Medicaid managed care separately by race/ethnicity. Specifically, we use three race/ethnicity categories: non-Hispanic, white; non-Hispanic, Black; and Hispanic of any race. Besides the inherent interest in whether or not Medicaid managed care had different effects by race/ethnicity, the stratification of our sample by race/ethnicity is advantageous in light of our research design that depends on differences in demographic characteristics to sort women by income and Medicaid participation. We elaborate on this below, but note that the same demographic characteristics will result in different income and insurance status distributions by race/ethnicity. For example, it is well known that incomes among Black families are lower than incomes of white families. Thus, among women with the same demographic characteristics, a higher proportion of Black pregnant women will by covered by Medicaid than White women. Changes over time in the race/ethnic composition of the demographic groups we use to stratify the sample may confound estimates of the effect of Medicaid managed care on health and health care utilization. Obtaining separate estimates by race/ethnicity avoids this potential problem.

\section{Dependent Variables}

We examine the effect of Medicaid managed care on a variety of dependent variables related to infant health. Among the most important inputs affecting infant health is prenatal care and we examine two variables that measure different aspects of such care: the total number of prenatal visits received; and a dichotomous indicator of whether the mother received inadequate prenatal care conditional on the timing of care initiation. ${ }^{6}$ Adequacy of prenatal care is measured

\footnotetext{
${ }^{6}$ In analyses not presented, we also used a dichotomous indicator of whether the mother initiated prenatal care after the first trimester (including no care) to measure prenatal care. Results from these analyses were similar to those presented.
} 
as having "intermediate" or "inadequate" care according to the Adequacy of Prenatal Care Utilization (APNCU) index (Kotelchuck 1994).

We measure infant health using a dichotomous indicator of whether the birth was of low weight (less than 2500 grams). We also examine the effect of Medicaid managed care on the incidence of preterm births, which are defined as births with a gestational age less than 37 weeks. While it may seem redundant to examine both LBW and pre-term birth, since pre-term birth is the most important proximate cause of LBW, examining both outcomes provides a type of specification test because of differences between the two outcomes in the scope of clinical intervention. In the case of pre-term birth, there is relatively little that can be done clinically to alter its incidence (Collaborative Group on Preterm Prevention 1993; Gibbs et al. 1993; Hack and Merkatz 1995; Tucker et al. 1991). In contrast, the scope of clinical intervention is greater for LBW, for example, through smoking cessation and nutrition programs. Therefore, Medicaid managed, which may change physician practice patterns and treatment, may affect LBW, but should have relatively little effect on pre-term birth. Estimates of the effect of Medicaid managed care should reflect these facts; estimates should be larger for LBW than pre-term birth. If estimates of the effect of Medicaid managed care are similar across the two outcomes, it is unlikely that we have identified a true managed care effect. Instead, this finding would suggest that there is some omitted variable that is affecting birth outcomes that is correlated with the implementation of Medicaid managed care.

Finally, we examine the impact of Medicaid managed care on the use of cesarean section to investigate directly whether Medicaid managed care affects patient care. Ultimately it is changes in provider practice patterns, either because of a change in provider or change in provider behavior induced by Medicaid managed care, that are required to bring about changes in Medicaid recipients utilization and health. In obstetrics, cesarean section is a relatively common procedure for which the physician has some discretion. Therefore, the incidence of cesarean section may be influenced by Medicaid managed care, which may cause a change in provider or a change in provider behavior. 


\section{Medicaid Managed Care Indicators}

As noted, birth certificates do not contain information on insurance status or Medicaid managed care participation. Therefore, we use information on the type of Medicaid managed care in the woman's county of residence at the time of birth and append it to information on the birth certificate. The county Medicaid managed care measures come from an Urban Institute survey of state Medicaid program directors. Thus, we only observe whether or not a woman gave birth in a county that has a particular type of Medicaid managed care program, not whether she is actually enrolled in the program.

The county Medicaid managed care implementation survey collected information from state Medicaid agencies on the start and end dates of managed care programs operating for children and adults in each county. ${ }^{7}$ Information was collected at the county level because many states phase in their programs, starting with a few, mainly urban, counties and later expanding to others. The survey indicates whether the county has a voluntary or mandatory PCCM or HMO. Many counties have multiple types of programs in a county at one time (e.g., mandatory PCCM programs and voluntary HMO programs). Where possible, the survey data were cross-checked with information from other sources, such as Medicaid managed care enrollment reports published by the Health Care Financing Administration and numerous case studies. As noted, Medicaid managed care programs fall into two broad plan types: primary care case management (PCCM) and health maintenance organization (HMO). PCCM programs contract with a primary care gatekeeper (e.g. physician, clinic) who coordinates primary and specialty care for Medicaid beneficiaries. HMO programs contract with an existing HMO, pre-paid health plan (PHP), or other institutional health care provider who, in addition to coordinating care assumes financial risk of providing covered services. There is great variation in the payment methods and other arrangements within PCCM and HMO types that are described in detail elsewhere (Hurley and Freund 1988, Hurley et al. 1993). Typically, PCCM programs are paid on a fee-for-service basis, plus a small monthly case management fee per enrollee, while HMO plans are paid a capitation rate. 
Using the information on the timing and location of Medicaid managed care program implementation, we construct eight indicators of the presence Medicaid managed care in a county: no Medicaid managed care (i.e., fee-for-service), mandatory PCCM or HMO, mandatory HMO only, mandatory PCCM only, mandatory PCCM or voluntary HMO, voluntary PCCM or HMO, voluntary HMO only, and voluntary PCCM only. ${ }^{8}$ We use these eight indicators to estimate a modified version of equation (2). Again, we acknowledge that there are important differences in Medicaid managed care programs within the broad groups we have created. Therefore, our results need to be interpreted as average effects.

Table 1 shows the variation by year in the number of states with Medicaid managed care programs. In general, there was significant expansion in Medicaid managed care during this period. For example, in 1991, only five states had at least one county with a mandatory HMO only plan, but by 1996, 20 states had at least one county with such plans. There were also significant differences in the growth of various types of programs; there was little growth in voluntary programs, but mandatory programs were greatly expanded between 1991 and 1996. Moreover, the proportion of births occurring in counties that had a Medicaid managed care program increased significantly during this period, as shown in Table 2 . In 1991, approximately 30 percent of all births to unmarried, women with fewer than 12 years of education occurred in a county with some type of Medicaid managed care program. ${ }^{9}$ By 1996 , this share rose to over 85 percent. Thus, up to 55 percent of this sample of women was affected by the switch to Medicaid managed care since, as we document below, virtually all of these women are eligible for Medicaid, and the vast majority of them were enrolled in Medicaid.

\footnotetext{
${ }^{7}$ AFDC-related groups include AFDC, AFDC-UP, poverty expansions (for children), and Medically Needy (depending on the state).

${ }^{8}$ We also experimented with alternative specifications of the policy variables. Specifically, we obtained estimates from a model that used a six-month lag for Medicaid managed care indicators, and from a model that used four nonmutually exclusive categories of Medicaid managed care (mandatory PCCM, mandatory HMO, voluntary PCCM, voluntary HMO). The estimates from these regressions lead to the same inferences as those reported in the text. ${ }^{9}$ We do not know whether a woman was covered by Medicaid or whether she was enrolled in a managed care program. Thus, the figures in Table 2 are upper bound estimates of the number of women affected.
} 


\section{Characteristics of the Mother and Child}

Characteristics of the mother are used to control for variation in outcomes due to differences in family preferences for child health, family income and the price of other infant health inputs (e.g., wages). Since we do not have direct measures of these variables, we use exogenous determinants of these factors. Thus, in addition to the mother's education, marital status and race, which we use to stratify the sample, we also include in the model age of the mother (six categories), birth order of the child (a dummy variable indicating first born), and an indicator of whether the mother was foreign born. ${ }^{10}$

As mentioned earlier, we estimate separate models by mother's socio-economic status, which we define using mother's education and marital status. The purpose of stratifying the sample by these characteristics is to identify women most likely to be covered by Medicaid, and thereby affected by the switch to Medicaid managed care. Marital status and education are strongly correlated with Medicaid participation. For the purposes of this analysis, we created four categories of pregnant women: married with less than 12 years of completed schooling; unmarried with less than 12 years of completed schooling; married with between 12 and 15 years of completed schooling; and unmarried with between 12 and 15 years of completed schooling.

We use data from the 1992 Current Population Survey (CPS) on women with infants to assess whether our four categories of women are a valid proxy for socioeconomic status and Medicaid participation. The CPS is a national probability sample of approximately 60,000 U.S. households conducted monthly by the U. S. Bureau of Labor Statistics. The March interview collects information on both income and health insurance coverage in the past year. We examine the sub-sample of women with infants at the time of the 1992 March survey, because they were pregnant during 1991, the first year of our study.

Table 3 presents information on average family income and health insurance status of pregnant

\footnotetext{
${ }^{10}$ We also estimated models that included variables that measure the health status of the mother prior to conception such as chronic hypertension, heart and lung disease, previous preterm births and previous births that were large for gestational age. These variables, while highly significant, had little effect on the estimates of the effect Medicaid managed care.
} 
women in 1991. The figures in Table 3 support our research strategy; marital status and education do a reasonably good job identifying pregnant women who are poor and covered by Medicaid. For example, Medicaid covered 85.2 percent of unmarried women with fewer than 12 years of education in 1991. In contrast, Medicaid covered only 12.6 percent of married women with 12 to 15 years of education.

Table 3

Income Distribution and Insurance Status of Pregnant Women 1991

\begin{tabular}{|l|c|c|c|c|}
\hline & $\begin{array}{c}\text { Average Family } \\
\text { Income }\end{array}$ & $\begin{array}{c}\text { Percentage with } \\
\text { Medicaid } \\
\text { Coverage }\end{array}$ & $\begin{array}{c}\text { Percentage with } \\
\text { Private Insurance } \\
\text { Coverage }\end{array}$ & $\begin{array}{c}\text { Percentage } \\
\text { Uninsured }\end{array}$ \\
\hline Unmarried, <12 Yrs. Edu. & $\$ 5,452$ & 85.2 & 11.4 & 3.42 \\
\hline Unmarried, 12-15 Yrs. Edu. & 8,336 & 65.0 & 30.4 & 4.62 \\
\hline Married, <12 Yrs. Edu. & 18,139 & 45.5 & 36.3 & 17.8 \\
\hline Married, 12-15 Yrs. Edu. & 34,690 & 12.6 & 76.2 & 9.4 \\
\hline
\end{tabular}

Source: Authors' tabulations of TRIM2 Edited version of March 1992 Current Population Survey (CPS).

The differences in Medicaid coverage by demographic group is essential to our research design, which is basically a pre-post comparison of prenatal care use and birth weight associated with the implementation of Medicaid managed care. Any observed pre-post differences may be the result of changes in prenatal care and birth weight that are unrelated to the introduction of Medicaid managed care. One way to assess this possibility is to examine pre-post differences of groups unaffected, or less affected, by the introduction of Medicaid managed care. The effect of Medicaid managed care should be roughly proportional to the number of women potentially affected by this policy change. ${ }^{11}$ Accordingly, we expect the largest effects for the group of unmarried women with fewer than 12 years of education and the smallest effects for the group of married women with 12 to 15 years of education. If this pattern does not emerge, for example if estimates across demographic groups were similarly sized, this would be evidence that the pre-post difference is measuring more general changes in prenatal care and birth weight that are unrelated to Medicaid managed care.

\footnotetext{
${ }^{11}$ If the effect of Medicaid managed care was constant across demographic groups, than the estimates obtained by our statistical analysis should be strictly proportional. However, to the extent that the effects of Medicaid managed care may differ by demographic group, estimates may not be strictly proportional. However, we do expect to observe larger effects for groups that are more affected by Medicaid managed care.
} 


\section{Results:}

Below we present the results from our regression analysis, which uses individual-level data from birth certificates to estimate the effect of Medicaid managed care on the following outcomes related to infant health: prenatal care use, incidence of low birth weight, pre-term birth, and cesarean section. Estimates are obtained by ordinary least squares regression using a model that includes controls for county fixed-effects and state-specific linear time trends. ${ }^{12}$ Analyses were done separately by race/ethnicity of the mother, and within each race/ethnicity group, separately by demographic characteristics of the mother. As noted, we used four different groups of women defined by education and marital status: unmarried women with fewer than 12 years of education, married women with fewer than 12 years of education, unmarried women with 12 to 15 years of education and married women with 12 to 15 years of education.

We present only the estimates associated with mandatory managed care programs and focus our discussion of the results on these programs. This choice reflects the fact that with the exception of HMOonly programs, there was little growth in voluntary managed care programs, as shown in Tables 1 and 2. Thus, from a policy perspective, it is the mandatory programs that are of most interest. Moreover, the estimates of the effects of voluntary programs are potentially biased because of non-random selection into such programs. Such selection should be less problematic in the case of mandatory programs, and therefore, estimates of the effects of these programs are more credible. For completeness, we have included an appendix with the entire set of estimates.

\section{Non-Hispanic, White Women}

We begin our review of the findings with the regression estimates obtained using a sample of white, non-Hispanic women. Estimates of the effect of Medicaid managed care are presented in Table 4, which has four columns of estimates. Each column lists estimates pertaining to one of the four groups defined by education and marital status with the group most likely to be enrolled in Medicaid in the first 
column and the group least likely to be enrolled in Medicaid in the fourth column. Therefore, we expect any estimates of the effect of Medicaid managed care to be larger in the first column than the fourth. Indeed, we expect estimates to become increasingly smaller from column 1 to column 4 since the proportion of women enrolled in Medicaid also becomes increasingly smaller and less significant from column 1 to column 4. In each column, estimates of the effect of Medicaid managed care are presented for several outcomes.

The first outcome presented is the number of prenatal care visits. Estimates indicate that women who lived in counties with a mandatory HMO Medicaid managed care program had fewer prenatal care visits than women who lived in counties with a mandatory PCCM program or traditional Medicaid. These estimates are quite small in magnitude, however, and suggest that such programs decreased the number of visits by between 0.03 (column 3, Mandatory PCCM) and 0.28 (column 1, Mandatory HMOonly) visits, or by between zero and two percent. In addition, the magnitudes of the estimates are similar across demographic groups, which is a finding contrary to expectations; as noted, we expect estimates to be the largest in column 1 and smallest in column 4. Estimates listed in appendix also indicate that women who lived in a county with a voluntary HMO-only managed care program had less prenatal care visits than women who lived in a county with traditional Medicaid. Again, the estimates are small in magnitude and similar across demographic groups. In sum, estimates presented in Table 4 suggest that mandatory Medicaid managed care programs were associated with a small, clinically unimportant decrease in the number of prenatal care visits. A causal interpretation of this finding, however, is unjustified because of the unexpected similarity of estimates across demographic groups.

The second outcome we examined was the incidence of inadequate prenatal care, defined as having "intermediate" or "inadequate" care according to the Adequacy of Prenatal Care Utilization (APNCU) index (Kotelchuck 1994). For this outcome, estimates are mixed: estimates associated with the policy indicators that have a mandatory PCCM component are negative, but estimates associated with a mandatory HMO-only are positive. However, for all of the managed care indicators, estimates of their

\footnotetext{
${ }^{12}$ In addition, year dummy variables were also included, which control for common (across states) year effects.
} 
effect on the incidence of inadequate prenatal care are relatively similar across demographic groups suggesting that these estimated effects are not causal. For example, a mandatory HMO-only program is associated with a 0.01 , or 2.3 percent, increase in the incidence of inadequate prenatal care among unmarried women with fewer than 12 years of schooling, almost all of whom are covered by Medicaid. It is therefore surprising that a mandatory HMO-only program has a similar estimated effect, 0.009 , or 4.3 percent, for married women with 12 to 15 years of schooling since few of these women are covered by Medicaid. Estimates of the effects of voluntary programs, which can be found in the appendix, indicate that voluntary PCCM programs are associated with a decrease in the incidence of inadequate prenatal care, but the similarity of estimates across demographic groups suggests that these estimated effects are not causal. In summary, the estimates in Table 4 related to prenatal care use, suggest that mandatory Medicaid managed care programs had little effect on prenatal care use, as measured by the APNCU index, of non-Hispanic White women. Estimates were small in magnitude, mostly insignificant and did not exhibit the expected pattern across demographic groups.

We next turn our attention to infant health. Specifically, we examined the effect of Medicaid managed care on the incidence of low birth weight (LBW) and pre-term birth. The estimates of the effect of Medicaid managed care on LBW and pre-term birth in Table 4 are all positive and statistically significant. Similar results were found for voluntary managed care programs (see appendix). Moreover, estimated effects are large; for example, a mandatory PCCM/HMO program is associated with an increase in the incidence of low birth weight of between 0.010 (column 4) and 0.020 (column 3), which represent an approximate 25 percent increase in the incidence of low birth weight. For both infant health outcomes, however, the magnitudes of the estimates within each row are similar across demographic groups, which is counter to expectations; estimates should be larger for groups with greater Medicaid enrollment who are more likely to be affected by the switch to managed care. ${ }^{13}$ Moreover, estimates of

\footnotetext{
${ }^{13}$ Estimates in the last column (married, 12-15 years of education) are smaller in absolute value than those in the previous three columns, but in relative terms, effects are approximately equal. In addition, for other demographic groups, estimates associated with birth weight are similarly sized even in absolute value. Thus, we do not believe the estimates in Table 5 reflect a causal effect.
} 
the effect of Medicaid managed care on pre-term birth are usually larger, both in absolute and relative terms, than estimates of the effect of Medicaid managed care on LBW. This finding is inconsistent with the clinical literature related to these two outcomes; Medicaid managed care should have a larger effect on the incidence of LBW since the scope of clinical intervention is greater for this outcome.

These results are difficult to interpret. The positive estimates associated with the managed care variables most likely reflect a general trend in these outcomes that is coincident with the introduction of Medicaid managed care. This conclusion is consistent with the absence of a causal relationship between Medicaid managed care and prenatal care use. Indeed, there was not even a statistical association between Medicaid managed care and prenatal care use that could explain these worsening birth outcomes, although the inputs to care could be different. While mandatory Medicaid managed care programs were associated with less prenatal care visits other types of Medicaid managed care programs were not, and not all mandatory programs were associated with an increase in inadequate prenatal care as defined by the APNCU index. However, all of the Medicaid managed care programs are associated with worse birth outcomes. Moreover, Medicaid managed care had similar effects on pre-term birth, which contradicts clinical experience. It is unlikely that these strong positive associations between Medicaid managed care and the incidence of low-birth weight are causal. Instead, estimates in Table 4 suggest some type of specification error-for example, an omitted variable.

To investigate this possibility, we re-estimated the birth weight regressions including the countyspecific number of neonatal intensive beds. The results did not change with the addition of this variable. We also estimated models restricted to urban counties, since many managed care plans were implemented in urban counties. Again, the results were basically unchanged from those reported. We also estimated models with lagged managed care indicators and these results were similar to those reported.

If we assume that the effect of this omitted variable is being measured by the estimates associated with groups unlikely to be affected by Medicaid managed care, then estimates in Table 4 suggest that 
Medicaid managed care had no effect on the incidence of low-birth weight and pre-term birth. ${ }^{14}$ In the absence of this assumption, we are prevented from drawing any firm conclusions, except perhaps that there is no evidence to suggest that Medicaid managed care had a positive effect on birth weight.

The last outcome we examined was the incidence of cesarean section. As can be observed, all but one estimate of the effect of Medicaid managed care on cesarean section is numerically negligible and statistically insignificant. Thus, there is no evidence that Medicaid managed care has affected this type of obstetrical procedure.

\section{Non-Hispanic, Black Women}

Table 5 presents a similar set of estimates as those just described, but in this case estimates were obtained using a sample of non-Hispanic, Black women. The presentation of the estimates in Table 5 is organized in exactly the same way as Table 4.

Estimates related to the number of prenatal care visits indicate that all of the mandatory Medicaid managed care programs listed in the table are associated with a reduction in the number of prenatal care visits; and nearly all of the estimates are statistically significant. In terms of magnitude, the estimates were relatively small: between -0.06 (column 4, Man. PCCM and Vol. HMO) and -0.47 (column 3, Mandatory PCCM/HMO), or between zero and five percent. Among the voluntary programs, estimates were mixed; voluntary HMO programs were associated with a decrease in prenatal care visits, but voluntary PCCM and voluntary mixed (PCCM and HMO) were associated with an increase in visits. If we examine the magnitudes of the estimates across demographic groups, however, we observe very similarly sized estimates. This pattern of results is inconsistent with a causal interpretation. We expected to find larger estimated effects among groups with greater Medicaid enrollment, but this is not what is observed. We believe that the significant associations we observe between Medicaid managed care and the number of prenatal care visits is due to a specification error. As noted above, under certain

\footnotetext{
14 In other words a difference-in-differences analysis would suggest a zero effect.
} 
assumptions, the similarity of the estimates across demographic groups imply that Medicaid managed care had no true effect. Absent this assumption, estimates in Table 5 suggest that Medicaid managed care had a small negative effect on the number of prenatal care visits.

A similar conclusion is suggested by the estimates of the effect of Medicaid managed care on the incidence of inadequate prenatal care utilization. For this outcome, there are fewer statistically significant associations. Moreover, even the statistically significant estimates that are related to these outcomes do not follow the expected pattern. Estimated effects of managed care on the incidence of inadequate prenatal care are largest for married women with 12 to 15 years of education, but this is the group that is least likely to be enrolled in Medicaid and therefore be affected by Medicaid managed care. In addition, estimates of the effect of mandatory PCCM and mandatory PCCM/HMO programs have opposite signs. It is difficult to reconcile these estimates given the similarity of the two types of programs. The estimates in Table 5 suggest that Medicaid managed care had no significant affect on the adequacy of prenatal care use of non-Hispanic, Black women.

Estimates in Table 5 of the effect of Medicaid managed care on LBW and pre-term birth are positive, large, and statistically significant. But the similarity of the estimates across all demographic groups suggests a spurious not causal relationship. It is also the case that Medicaid managed care has a larger association in both absolute and relative terms with pre-term birth than it does with LBW. As noted above, this is surprising given that the limited scope of clinical intervention associated with preterm birth. And the evidence related to prenatal care is inconsistent with the estimates related to birth weight and pre-term birth. Some of the estimates related to prenatal care indicated that Medicaid managed care increased the number of prenatal care visits and decreased the incidence of inadequate prenatal care, but all of the birth weight estimates indicate that Medicaid managed care increased adverse outcomes. To sum-up, we believe the appropriate interpretation of the estimates is that there is no causal relationship between Medicaid managed care and LBW among non-Hispanic Black women, but that general trends in this outcome were correlated with the switch to Medicaid managed care; estimates in 
Table 5 reflect this coincidence. Clearly, there is little evidence to suggest that Medicaid managed care improved birth outcomes.

Finally, estimates in Table 5 indicate that Medicaid managed care had no numerically important or statistically significant relationship to the incidence of cesarean section among non-Hispanic, Black women. The one exception is the mandatory HMO-only managed care programs. In this case, estimates suggest that these types of programs increased the use of cesarean section among groups likely to be affected. The magnitudes of the estimates across demographic groups are consistent with expectations; the largest effects are found among groups with the greatest Medicaid enrollment and there is no statistically significant association among groups least likely to be enrolled in Medicaid.

\section{Hispanic (any race) Women}

The last race/ethnicity group we obtained estimates for was Hispanic women, who can be of any race. Estimates of the effects of Medicaid managed care on this group's use of prenatal care and cesarean section, and their infants' birth weight are presented in Table 6. In general, the estimates in Table 6 lead to a conclusion similar to those reached for the other two race/ethnicity groups. The statistical associations between Medicaid managed care programs and prenatal care use are mixed; some types of programs are associated with an increase in prenatal care use and others are associated with a decrease in such use. However, as a whole, the estimates related to prenatal care do not support the hypothesis that there is a causal relationship between Medicaid managed care programs and prenatal care use. The primary reason for this conclusion is that estimates of the effect of managed care are not even roughly proportional to the proportion of women potentially affected by managed care. In several cases the largest estimates are associated with the group least likely to be affected by managed care. In general, there is evidence that Medicaid managed care was associated with a slight decrease in the number of prenatal care visits, but the decrease was unimportant from a clinical perspective. For the adequacy of prenatal care measure, estimates in Table 6 were small in magnitude, often not statistically significant, 
and indicated both positive and negative effects. These results suggest that Medicaid managed care had no significant effect on this outcome.

As was the case for the other two racial/ethnic groups studied, estimates of the effect of Medicaid managed care on LBW and pre-term birth were uniformly positive, statistically significant, and large in magnitude. Also similar to the other groups, the pattern of the estimates undermines a causal interpretation of such estimates. Estimates of the effect of Medicaid managed care on pre-term birth are usually larger than estimates of the effect of Medicaid managed care on low birth weight, and the largest estimates of the effect of Medicaid managed care are not always observed among the groups most likely affected by managed care. The likely mis-specification of the empirical model prevents firm conclusions, but if we are willing to assume that some of the demographic groups are a good comparison group for others, the estimates in Table 6 suggest that Medicaid managed care had no effect on LBW and pre-term birth. In any case, results appear to rule out a conclusion that Medicaid managed care improved birth outcomes. Finally, nearly all of the estimates of the effect of Medicaid managed care on cesarean section were small and statistically insignificant.

\section{Single State Analyses}

While we have argued that a national evaluation has advantages related to statistical power and broad applicability of results, a disadvantage of such an evaluation is the loss of detailed information about managed care policies in individual states. For example, some states have generous reimbursement rates compared to others and the effect of managed care may be state-specific. To investigate this issue, we re-estimate the birth weight model for non-Hispanic white women for seven states that differed by their fee generosity and other aspects of implementation. The seven states are: CA, CO, FL, MI, PA, TN and WA. Information on fees and program implementation was taken from Holahan, Rangarajan, and Schirmer (HRS) (1999). To provide some idea of the variation in fees, Medicaid reimbursement in California for obstetrical services were about 70 percent of the national average, whereas in Florida, similar fees were 120 percent of the national average in 1993. 
We obtained estimates for each state separately and the results are listed in Table $7 .^{15}$ Generally, the results in Table 7 are consistent with those in Table 4, and show that Medicaid managed care was associated with an increase in the rate of low-birth weight for all four of the demographic groups.

Surprisingly, California is the only state that does not fit this pattern even though it had relatively low fees relative to other states. The upshot is that the national estimates presented earlier do not seem to hide much individual state heterogeneity.

\section{Discussion:}

In the early 1990s states began to increase their use of managed care organizations to provide health care to the Medicaid population. This policy was likely driven by the desire to contain costs. Medicaid expenditures had been rapidly increasing during the preceding period and states were looking for a way to reduce outlays that did not rely on lowering reimbursement rates that were already quite low. Moreover, the private sector experience with managed care had begun to pay off with moderate annual increases in health expenditures. So the adoption of managed care proceeded even though there was limited empirical evidence as to the effect of Medicaid managed care on the health and health care utilization of Medicaid recipients.

In this study, we addressed the gap in empirical evidence related to the effect of Medicaid managed care on health. This is important because as we have argued, an important criterion to evaluate the success of Medicaid managed care should be its effect—relative to traditional Medicaid—on health. We presented an extensive analysis of the effect of Medicaid managed care programs on prenatal care, an important determinant of infant health, and birth weight, an important measure of infant health.

Specifically, our analysis examined all births in the United States to four groups of women between 1991 and 1996 to investigate whether there was a systematic relationship between the presence of a Medicaid

\footnotetext{
${ }^{15}$ Dubay and Kenney also carried out a similar analysis for Missouri using data with the additional advantage of identifying women covered by Medicaid (Sommers, Anna, Lisa Dubay, and Genevieve Kenney, 2002). The results of that analysis were very similar to those reported here-Medicaid managed care was associated with an increase in the incidence of low-birth weight.
} 
managed care program and prenatal care use, cesarean section, birth weight and pre-term birth. Analyses were done separately by race/ethnicity of the mother using three groups: non-Hispanic, White; nonHispanic, Black; and Hispanic (any race) women. The results of these analyses suggested the following:

- Medicaid managed care was associated with a small, clinically unimportant decrease in the number of prenatal care visits, although a similar relationship was not found for an alternative measure of the adequacy of prenatal care- the APNCU index.

- Medicaid managed care was associated with a significant increase in the incidence of low-birth weight and pre-term birth.

- Medicaid managed care had no association with the incidence of cesarean section.

We have argued that a causal interpretation of the first two findings is unjustified. In the case of prenatal care, our argument relies on the fact that estimates across demographic groups that differed significantly in their likelihood of being affected by Medicaid managed care were similar. For birth outcomes, a parallel argument was used that was bolstered by the argument related to the similarity of estimates of the effect of Medicaid managed care for LBW and pre-term birth. If we assume that the groups in the analysis sample that are unlikely to be affected by Medicaid managed care are good comparison groups for groups in the analysis sample that are likely to be affected, then estimates imply that Medicaid managed care had virtually no association with or causal effect on prenatal care use and birth outcomes. In fact, this is our preferred conclusion.

The policy implication of our findings is that the switch to Medicaid managed care has not adversely affected infant health, as measured by birth weight. Therefore, it provides some justification for the switch to managed care since Medicaid managed care has been successful at slowing the growth in health care expenditures (Leibowitz 2001). As noted, however, more study needs to be undertaken. Birth weight is a limited measure of infant health and there may be effects of Medicaid managed care on other aspects of infant health. In addition, our study was limited by the fact that we did not know who was actually enrolled in Medicaid and affected by the switch to Medicaid managed care. While we believe that our strategy to address this problem was credible, it would have obviously been better if we had 
information on enrollment in Medicaid. Finally, our classification of Medicaid managed care programs was crude, as there is much greater diversity in programs than reflected in our specification. This black box approach limited us to statements about the average effect of programs in our broad categories. While these are meaningful for policymakers, they may obscure a significant amount of heterogeneity among programs within each category.

Clearly, more study is needed to understand what is responsible for the relatively large increases in low birth-weight and pre-term births that were observed in counties that adopted managed care over the 1990-1996 time period. Nationally, fetal death rates were declining over this period, potentially due in part to the increased use of technology in the neonatal period. To the extent that increased use of technology was concentrated in urban areas, and particularly in the areas that moved to managed care in Medicaid, that could explain the association found between Medicaid managed care and low birth weight and pre-term births. When we examined this possibility by controlling for changes in neonatal intensive care unit beds, and by restricting our sample to urban counties, our results did not change, but, it could be that neonatal intensive care unit beds are not a good proxy for the availability of technology. Finally, we can not rule out the possibility that women of higher socio-economic status were also exposed to changes in their service delivery systems, for example through increasing reliance on managed care in the private sector. But again, it is not clear whether and how such changes might have contributed to the increasing rates of pre-term and low birth-weight births occurring over this time period. 


\section{References}

Bergman, D. A. and C. J. Homer, 1998. Managed Care and the quality of children's health services. The Future of Children, Children and Managed Health Care, Vol.8, No.2. 60-75.

Collaborative Group on Pre-term Birth Prevention, 1993. Multicenter randomized, controlled trial of a preterm birth prevention program. Am. J. Obstet. Gynecol., 169, 352-366.

Cowan, Cathy et al. 1999. "National Health Expenditures, 1998." Health Care Financing Review 21(2): 165-210.

Culyer, A. J. and A. Wagstaff, 1993. Equity and equality in health and health care. Journal of Health Economics 12, 431-457.

Dubay, Lisa, Robert Kaestner and Timothy Waidmann. 2001. "Medical Malpractice Liability and its Effect on Prenatal Care Utilization and Infant Health." Journal of Health Economics 20(4): 591612.

Dubay, Lisa, Ted Joyce, Robert Kaestner and Genevieve Kenney. 2001. "Changes in Prenatal Care Timing and Low Birth Weight by Race and Socioeconomic Status: Implications for the Medicaid Expansions for Pregnant Women.” Health Services Research 36(2): 373-398.

Dubay, Lisa, Robert Kaestner and Timothy Waidman. 1999. "The Impact of Malpractice Fears on Cesarean Section Rates.” Journal of Health Economics 18(4):491-522.

Freund D.A., L. F. Rossiter, P. D. Fox, J. A. Meyer, R. E. Hurley, T. S. Carey and J. E. Paul, 1989. Evaluation of the Medicaid competition demonstrations. Health Care Financing Review. Vol. 11, No. 2, 81-97.

Freund D. A., T. J. Kniesner and A.T. LoSasso, April 1996. How Managed Care affects Medicaid utilization: A synthetic difference-in-differences zero-inflated count model. Center for Economic Research.

Friedman, M., 2001. How to Cure Health Care. Public Interest, 142, 3-30.

Gadomski, A., P. Jenkins and M. Nichols, 1998. Impact of a Medicaid primary care provider and preventive care on pediatric hospitalization. Pediatrics, Vol.101, No.3, 1-10.

Garrett, B., A. Davidoff and A. Yemane, 2001. The effect of Medicaid Managed Care on health service access and utilization: Evidence from the National Health Interview Survey 1991-1995. The Urban Institute.

Gavin N.I., M.C.Farrelly and J B. Simpson, Jr, 1998. Children's use of primary and preventive care under Medicaid Managed Care. Health Care Financing Review, Vol.19. No.4. 45-68.

Gibbs R.S., R. Romero, S.L. Hillier, D.A. Eschenbach and R.L. Sweet, 1992. A review of premature birth and subclinical infection. Am. J. Obstetr. Gynecol., 166(5), 1515-1528.

Glied, S., J. Sisk, S. Gorman and M. Ganz,1997. Selection marketing and Medicaid Managed Care. National Bureau of Economic Research, Working Paper: 6164.

Glied, S. 2000. Managed Care. Handbook of Health Economics, Vol.1B. (North-Holland, Amsterdam). 
Griffin, J. F., J. W. Hogan, J. S. Buechner and T. M. Leddy. 1999. The effect of a Medicaid Managed Care program on the adequacy of prenatal care utilization in Rhode Island. American Journal of Public Health, Vol. 89, No.4, 497-501.

Hack, M. and I. Merkatz,, 1995. Preterm delivery and low birth weight - a dire legacy. NE J. Med. 333, 1772-1773.

Health Care Financing Administration (HCFA), 2000. A Profile of Medicaid: Chartbook 2000. Washington, DC: US Department of Health and Human Services.

Hohlen M. M., L. M. Manheim, G.V. Fleming, S.M. Davidson, B.K. Yudkowsky, S.M. Werner and G. M. Wheatley, 1990. Access to office-based physicians under capitation reimbursement and Medicaid case management: Findings from the children's Medicaid program. Medical Care Vol. 28, No.1, 59-68.

Hurley, R. E., D. A. Freund and D. E. Taylor, 1989. Emergency room use and primary care case management: Evidence from four Medicaid demonstration programs. American Journal of Public Health, Vol.79, No.7, 843-846.

Kotelchuck, M., 1994. An evaluation of the Kessner adequacy of prenatal care index and a proposed adequacy of prenatal care utilization index. Am. J. Public Health 84, 1414-1420.

Krieger J. W., F. A. Connell and J. P. LoGerfo. 1992. Medicaid prenatal care: A comparison of use and outcomes in free-for-service and managed care. Am. J. Public Health, Vol. 82, No.2, 185-190.

Leibowitz, A. 2001. Medicaid managed care for children and youth: Managing costs or managing care? Paper prepared for conference on "Changing Welfare", University of Illinois at Chicago.

Leibowitz, A., J.L. Buchanan, J. Mann, 1992. A randomized trial to evaluate the effectiveness of a Medicaid HMO, Journal Of Health Economics (11)3 (1992) pp. 235-257

Levinson, A. and F. Ullman 1998. Medicaid Managed Care and infant health. Journal of Health Economics, 17, 351-368.

Long, S. and T. Coughlin, 2001. Impacts of Medicaid Managed Care on children. Health Services Research 36:1, 7-23.

Mauldon, J., A. Leibowitz, J. L. Buchanan, C. Damberg and K. A. McGuigan, 1994. Rationing or rationalizing children's medical care: Comparison of a Medicaid HMO with free-for-service care. Am J. Public Health Vol. 84, No.6, 899-904.

Miller R.H. and H.S. Luft, 1997. Does managed care lead to better or worse quality of care? Health Affairs, 16(5), 7-25.

Moreno, L., 1999. The Influence of TennCare on Perinatal Outcomes. A report submitted to The Office of Strategic Planning, Health Care Financing Administration. Mathematica Policy Research, Inc.

Newacheck PW, Hughes DC, Stoddard JJ. Children's access to primary care: differences by race, income, and insurance status. Pediatrics. 1996; 97: 26-32. 
Newacheck PW, Stoddard JJ, Hughes DC, Pearl M. Health insurance and access to primary care for children. N Engl J Med. 1998;338:513-9.

Newhouse, J., 1993. Free for All? Lessons from the RAND Health Insurance Experiment. Harvard University Press.

Sisk, J.E., S. A. Gorman, A. L. Reisinger, S. A. Glied, W. H. DuMouchel. and M. M. Hynes, 1996. Evaluation of Medicaid Managed Care: Satisfaction, access and use. The Journal of American Medical Association. Vol. 276, 50-55.

Sommers, Anna, Lisa Dubay, and Genevieve Kenney. 2002. Mandatory Medicaid managed care in Missouri: A difference-in-difference approach to evaluating effects on prenatal care use and infant birth weight. Urban Institute Working Paper.

Szilalgyi, P. G., 1998. Managed Care for children: Effects on access to care and utilization of health services. The Future of Children, Children and Managed Health Care, Vol.8, No.2.39-59.

Tucker, J.M., R. L. Goldenberg, R.O. Davis, R.L. Copper, C.L.Winkler, and J.C. Hauth, 1991. Etiologies of preterm birth in an indigent population: Is prevention a logical expectation? Obstet. Gynecol.77, 343-347.

West, D.W., M.E. Stuart, A.K. Duggan and C.D. DeAngelis, 1996. Evidence for selective Health Maintenance Organization enrollment among children and adolescents covered by Medicaid. Arch Pediatr Adolesc Med, Vol.150, 503-507.

Zuckerman, S. and N. Brennan, 2001. Medicaid Managed Care and Beneficiary Access and Use. Health Policy Center, The Urban Institute. 
Table 1

Number of States with a Medicaid Managed Care Program, 1990-1996

\begin{tabular}{|c|c|c|c|c|c|c|c|}
\hline \multirow[b]{2}{*}{ Year } & \multicolumn{2}{|c|}{ Mixed PCCM/HMO } & \multicolumn{2}{|c|}{ HMO Only } & \multicolumn{2}{|c|}{ PCCM Only } & \multirow{2}{*}{$\begin{array}{c}\text { Mand. PCCM } \\
\text { Vol. HMO }\end{array}$} \\
\hline & Voluntary & Mandatory & Voluntary & Mandatory & Voluntary & Mandatory & \\
\hline 1991 & 4 & 2 & 14 & 5 & 5 & 5 & 1 \\
\hline 1992 & 5 & 2 & 14 & 6 & 6 & 10 & 3 \\
\hline 1993 & 4 & 2 & 12 & 6 & 5 & 13 & 5 \\
\hline 1994 & 4 & 4 & 13 & 10 & 5 & 21 & 6 \\
\hline 1995 & 3 & 4 & 14 & 13 & 5 & 20 & 7 \\
\hline 1996 & 3 & 8 & 12 & 20 & 6 & 21 & 8 \\
\hline
\end{tabular}

Note: A state is included in the count if it has at least one county with a Medicaid managed care program of the type specified. Thus, the number of state will add up to more than 51 (including D.C.) since some state had multiple types of programs.

Table 2

Percentage of Births Occurring in Counties with Medicaid Managed Care Programs, 1990-1996 Unmarried Women with 12 or Fewer Years of Education

\begin{tabular}{|c|c|c|c|c|c|c|c|c|}
\hline \multirow[b]{2}{*}{ White } & \multicolumn{3}{|c|}{ Mixed PCCM/HMO } & \multicolumn{2}{|c|}{ HMO Only } & \multicolumn{2}{|c|}{ PCCM Only } & \multirow[t]{2}{*}{ Total } \\
\hline & Voluntary & Mandatory & M.P/V.H & Voluntary & Mandatory & Voluntary & Mandatory & \\
\hline 1991 & 1 & 1 & 0 & 14 & 3 & 2 & 4 & 25 \\
\hline 1992 & 3 & 1 & 1 & 15 & 4 & 3 & 5 & 32 \\
\hline 1993 & 5 & 1 & 3 & 13 & 4 & 3 & 8 & 34 \\
\hline 1994 & 3 & 1 & 6 & 12 & 5 & 3 & 11 & 41 \\
\hline 1995 & 3 & 3 & 10 & 12 & 11 & 3 & 15 & 57 \\
\hline 1996 & 3 & 6 & 11 & 11 & 15 & 2 & 16 & 64 \\
\hline Black & & & & & & & & \\
\hline 1991 & 4 & 1 & 0 & 22 & 3 & 1 & 1 & 32 \\
\hline 1992 & 5 & 1 & 1 & 25 & 3 & 2 & 3 & 40 \\
\hline 1993 & 6 & 1 & 3 & 23 & 3 & 2 & 4 & 42 \\
\hline 1994 & 3 & 1 & 7 & 22 & 4 & 2 & 6 & 43 \\
\hline 1995 & 3 & 1 & 13 & 20 & 7 & 2 & 10 & 56 \\
\hline 1996 & 4 & 4 & 14 & 17 & 10 & 1 & 11 & 61 \\
\hline
\end{tabular}


Table 4

Estimates of the Effect of Medicaid Managed Care on Maternal and Infant Health non-Hispanic, White Women, 1990-1996

\begin{tabular}{|c|c|c|c|c|c|c|c|c|}
\hline \multirow[b]{2}{*}{ Outcome } & \multicolumn{2}{|c|}{$<12$, Unmarried } & \multicolumn{2}{|c|}{ 12-15, Unmarried } & \multicolumn{2}{|c|}{$<12$, Married } & \multicolumn{2}{|c|}{ 12-15, Married } \\
\hline & $\beta$ & p-Value & $\beta$ & p-Value & $\beta$ & p-Value & $\beta$ & p-Value \\
\hline Num. Prenatal Visits & $\mu=10.4$ & & $\mu=11.0$ & & $\mu=10.9$ & & $\mu=12.07$ & \\
\hline Mandatory PCCM/HMO & $-0.202 * *$ & 0.000 & $-0.117 * *$ & 0.003 & $-0.194 * *$ & 0.002 & $-0.110 * *$ & 0.002 \\
\hline Mandatory - HMO & $-0.275^{* *}$ & 0.000 & $-0.202 * *$ & 0.000 & $-0.255^{* *}$ & 0.000 & $-0.136 * *$ & 0.000 \\
\hline $\begin{array}{l}\text { Inadequate Prenatal Care } \\
\text { (APNCU) }\end{array}$ & $\mu=0.42$ & & $\mu=0.34$ & & $\mu=0.36$ & & $\mu=0.21$ & \\
\hline Mandatory PCCM/HMO & -0.011 & 0.063 & $-0.010 *$ & 0.024 & -0.003 & 0.631 & -0.005 & 0.254 \\
\hline Low Birth Weight & $\mu=0.085$ & & $\mu=0.068$ & & $\mu=0.067$ & & $\mu=0.041$ & \\
\hline Mandatory PCCM/HMO & $0.020 * *$ & 0.000 & $0.017^{* *}$ & 0.000 & $0.017 * *$ & 0.000 & $0.010 * *$ & 0.000 \\
\hline Mandatory - HMO & $0.012 * *$ & 0.000 & $0.012 * *$ & 0.000 & $0.013 * *$ & 0.000 & $0.006^{* *}$ & 0.000 \\
\hline Mandatory - PCCM & $0.014 * *$ & 0.000 & $0.008 * *$ & 0.000 & $0.008 * *$ & 0.000 & $0.005 * *$ & 0.000 \\
\hline Man. PCCM / Vol. HMO & $0.011 * *$ & 0.000 & $0.014 * *$ & 0.000 & $0.011 * *$ & 0.000 & $0.007 * *$ & 0.000 \\
\hline Preterm Birth & $\mu=0.118$ & & $\mu=0.102$ & & $\mu=0.097$ & & $\mu=0.073$ & \\
\hline Mandatory PCCM/HMO & $0.028 * *$ & 0.000 & $0.032 * *$ & 0.000 & $0.031^{* *}$ & 0.000 & $0.019 * *$ & 0.000 \\
\hline Mandatory - HMO & $0.025 * *$ & 0.000 & $0.021 * *$ & 0.000 & $0.025 * *$ & 0.000 & $0.013 * *$ & 0.000 \\
\hline Mandatory - PCCM & -0.002 & 0.333 & 0.000 & 0.932 & 0.003 & 0.222 & -0.001 & 0.723 \\
\hline Man. PCCM / Vol. HMO & -0.001 & 0.782 & -0.002 & 0.507 & 0.006 & 0.089 & 0.004 & 0.159 \\
\hline Num. of Observations & $1,134,473$ & & $1,835,800$ & & $1,143,919$ & & $1,985,594$ & \\
\hline
\end{tabular}

Notes: Estimates were obtained using ordinary least squares regression. All regression models include the following variables: county fixed effects, mother's age ( 8 dummy variables), a dummy variable indicating that mother was foreign born, a dummy variable indicating first birth, year (6 dummy variables), and state-specific linear trend. The number of observations listed in the table refers to the analysis of the number of prenatal care visits. For other outcomes, the sample size may be slightly larger or smaller. Due to the large size of the population of white, married women with 12 to 15 years of education, a 25 percent sample was used in the analysis. 
Table 5

Estimates of the Effect of Medicaid Managed Care on Maternal and Infant Health non-Hispanic, Black Women, 1990-1996

\begin{tabular}{|c|c|c|c|c|c|c|c|c|}
\hline \multirow[b]{2}{*}{ Outcome } & \multicolumn{2}{|c|}{$<12$, Unmarried } & \multicolumn{2}{|c|}{ 12-15, Unmarried } & \multicolumn{2}{|c|}{$<12$, Married } & \multicolumn{2}{|c|}{ 12-15, Married } \\
\hline & $\beta$ & p-Value & $\beta$ & p-Value & $\beta$ & p-Value & $\beta$ & p-Value \\
\hline Num. Prenatal Visits & $\mu=8.8$ & & $\mu=10.0$ & & $\mu=9.7$ & & $\mu=11.3$ & \\
\hline Mandatory PCCM/HMO & $-0.291 * *$ & 0.000 & $-0.393 * *$ & 0.000 & $-0.467 *$ & 0.028 & $-0.315^{* *}$ & 0.000 \\
\hline Mandatory - HMO & $-0.386 * *$ & 0.000 & $-0.438 * *$ & 0.000 & $-0.431 *$ & 0.017 & $-0.248 * *$ & 0.000 \\
\hline $\begin{array}{l}\text { Inadequate Prenatal Care } \\
\text { (APNCU) }\end{array}$ & $\mu=0.53$ & & $\mu=0.42$ & & $\mu=0.45$ & & $\mu=0.28$ & \\
\hline Mandatory PCCM/HMO & -0.016 & 0.054 & $-0.015^{*}$ & 0.020 & 0.019 & 0.401 & $-0.018 *$ & 0.029 \\
\hline Low Birth Weight & $\mu=0.140$ & & $\mu=0.122$ & & $\mu=0.121$ & & $\mu=0.093$ & \\
\hline Mandatory PCCM/HMO & $0.042 * *$ & 0.000 & $0.051 * *$ & 0.000 & $0.055 * *$ & 0.000 & $0.046 * *$ & 0.000 \\
\hline Mandatory - HMO & $0.025 * *$ & 0.000 & $0.031 * *$ & 0.000 & 0.020 & 0.119 & $0.018 * *$ & 0.000 \\
\hline Mandatory - PCCM & $0.012 * *$ & 0.000 & $0.018 * *$ & 0.000 & $0.022 * *$ & 0.002 & $0.014 * *$ & 0.000 \\
\hline Man. PCCM / Vol. HMO & $0.030 * *$ & 0.000 & $0.030 * *$ & 0.000 & $0.023 * *$ & 0.007 & $0.025 * *$ & 0.000 \\
\hline Preterm Birth & $\mu=0.204$ & & $\mu=0.175$ & & $\mu=0.174$ & & $\mu=0.140$ & \\
\hline Mandatory PCCM/HMO & $0.074 * *$ & 0.000 & $0.079 * *$ & 0.000 & $0.108 * *$ & 0.000 & $0.065 * *$ & 0.000 \\
\hline Mandatory - HMO & $0.048 * *$ & 0.000 & $0.042 * *$ & 0.000 & $0.034 *$ & 0.039 & $0.023 * *$ & 0.000 \\
\hline Mandatory - PCCM & 0.001 & 0.751 & -0.000 & 0.997 & 0.010 & 0.157 & 0.005 & 0.108 \\
\hline Man. PCCM / Vol. HMO & $0.009 * *$ & 0.003 & -0.003 & 0.285 & -0.002 & 0.845 & -0.001 & 0.722 \\
\hline Num. of Observations & $1,040,518$ & & $1,617,698$ & & 133,243 & & 872,744 & \\
\hline
\end{tabular}

Notes: Estimates were obtained using ordinary least squares regression. All regression models include the following variables: county fixed effects, mother's age ( 8 dummy variables), a dummy variable indicating that mother was foreign born, a dummy variable indicating first birth, year (6 dummy variables), and state-specific linear trend. The number of observations listed in the table refers to the analysis of the number of prenatal care visits. For other outcomes, the sample size may be slightly larger or smaller. Due to the large size of the population of white, married women with 12 to 15 years of education, a 25 percent sample was used in the analysis. 
Table 6

Estimates of the Effect of Medicaid Managed Care on Maternal and Infant Health Hispanic (any race) Women, 1990-1996

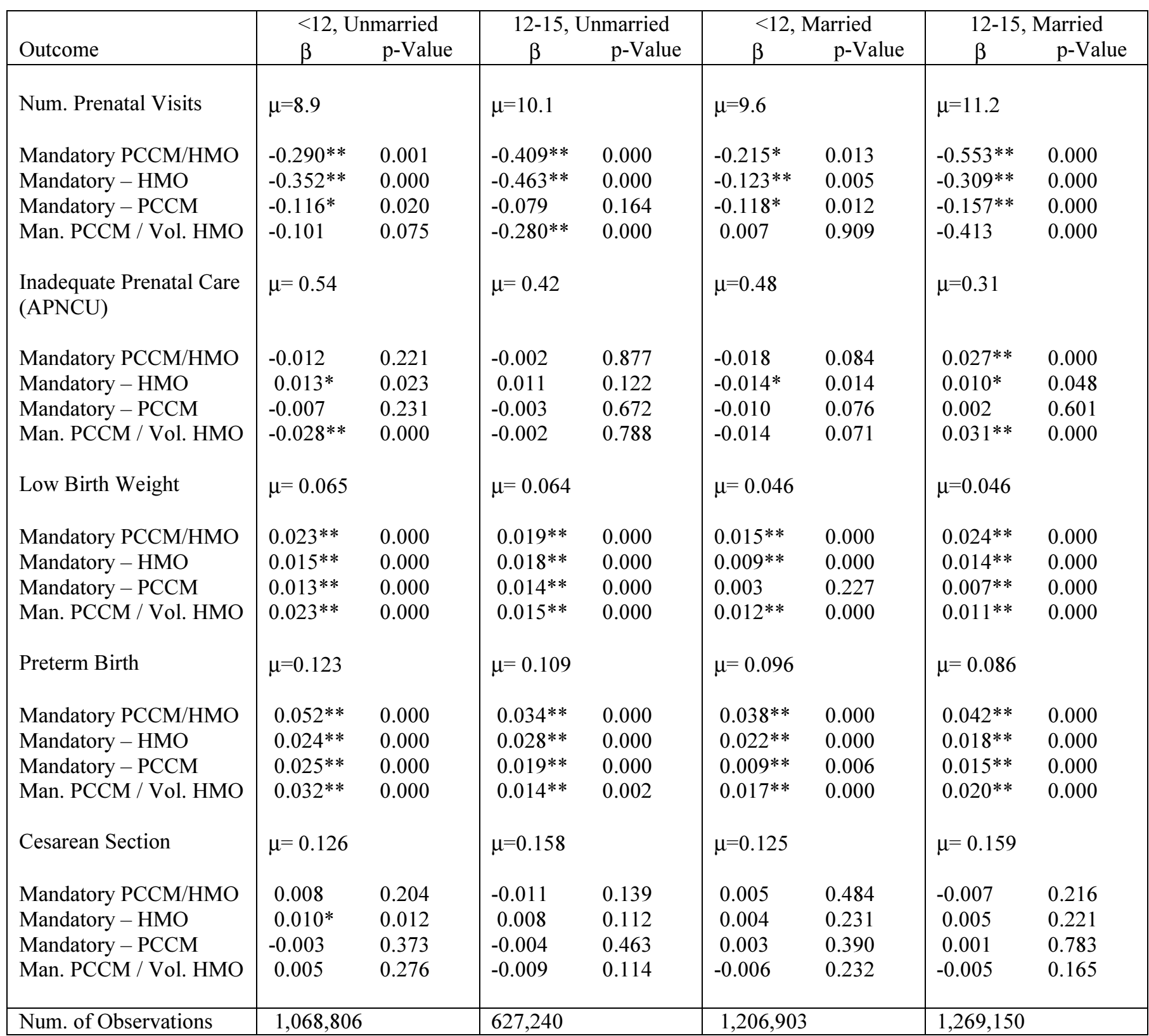

Notes: Estimates were obtained using ordinary least squares regression. All regression models include the following variables: county fixed effects, mother's age ( 8 dummy variables), a dummy variable indicating that mother was foreign born, a dummy variable indicating first birth, year (6 dummy variables), and state-specific linear trend. The number of observations listed in the table refers to the analysis of the number of prenatal care visits. For other outcomes, the sample size may be slightly larger or smaller. Due to the large size of the population of white, married women with 12 to 15 years of education, a 25 percent sample was used in the analysis. 


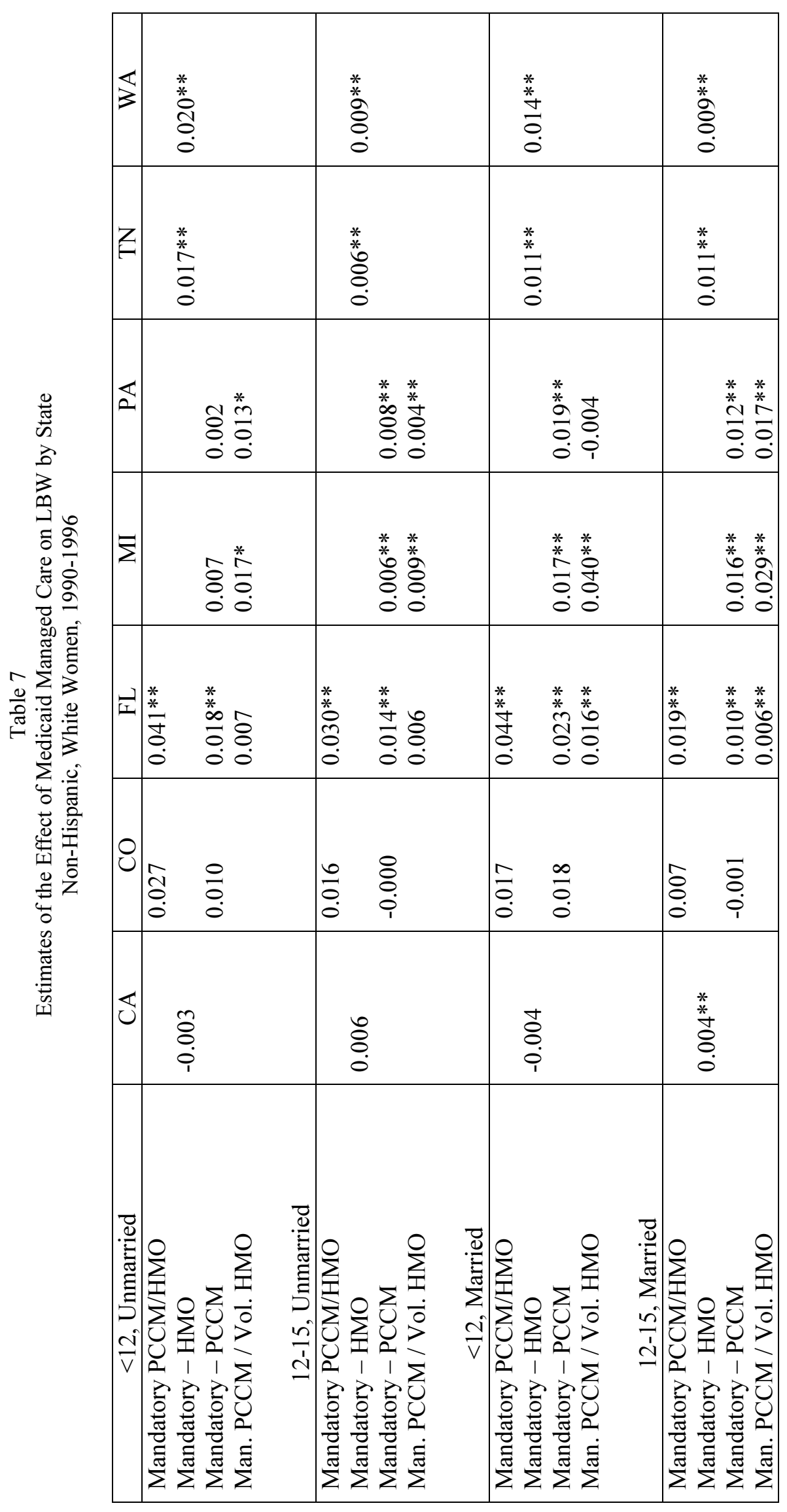


Appendix A 
Table A4. Estimates of the Effect of Medicaid Managed Care on Maternal and Infant Health non-Hispanic, White Women, 1990-1996

\begin{tabular}{|c|c|c|c|c|c|c|c|c|}
\hline \multirow[b]{2}{*}{ Outcome } & \multicolumn{2}{|c|}{$<12$, Unmarried } & \multicolumn{2}{|c|}{ 12-15, Unmarried } & \multicolumn{2}{|c|}{$<12$, Married } & \multicolumn{2}{|c|}{ 12-15, Married } \\
\hline & $\beta$ & $\mathrm{p}$-Value & $\beta$ & $\mathrm{p}$-Value & $\beta$ & $p$-Value & $\beta$ & $p$-Value \\
\hline Num. Prenatal Visits & $\mu=10.4$ & & $\mu=11.0$ & & $\mu=10.9$ & & $\mu=12.07$ & \\
\hline Mandatory PCCM/HMO & $-0.202 * *$ & 0.000 & $-0.117 * *$ & 0.003 & $-0.194 * *$ & 0.002 & $-0.110 * *$ & 0.002 \\
\hline Mandatory - HMO & $-0.275^{* *}$ & 0.000 & $-0.202 * *$ & 0.000 & $-0.255^{* *}$ & 0.000 & $-0.136^{* *}$ & 0.000 \\
\hline Mandatory - PCCM & -0.031 & 0.281 & 0.018 & 0.399 & -0.031 & 0.278 & 0.013 & 0.461 \\
\hline Man. PCCM / Vol. HMO & $-0.162 * *$ & 0.000 & $-0.126^{* *}$ & 0.000 & $-0.091 *$ & 0.035 & $-0.090 * *$ & 0.000 \\
\hline Voluntary PCCM/HMO & $0.090^{*}$ & 0.046 & 0.017 & 0.611 & 0.091 & 0.063 & -0.032 & 0.256 \\
\hline Voluntary - HMO & $-0.115^{* *}$ & 0.000 & $-0.106^{* *}$ & 0.000 & $-0.122 * *$ & 0.000 & $-0.089 * *$ & 0.000 \\
\hline Voluntary - PCCM & $-0.145^{* *}$ & 0.003 & -0.060 & 0.075 & 0.036 & 0.500 & 0.019 & 0.522 \\
\hline $\begin{array}{l}\text { Inadequate Prenatal Care } \\
\text { (APNCU) }\end{array}$ & $\mu=0.42$ & & $\mu=0.34$ & & $\mu=0.36$ & & $\mu=0.21$ & \\
\hline Mandatory PCCM/HMO & -0.011 & 0.063 & $-0.010^{*}$ & 0.024 & -0.003 & 0.631 & -0.005 & 0.254 \\
\hline Mandatory - HMO & $0.010^{*}$ & 0.020 & $0.007 *$ & 0.033 & $0.011^{*}$ & 0.023 & $0.009 * *$ & 0.002 \\
\hline Mandatory - PCCM & $-0.014 * *$ & 0.000 & $-0.014 * *$ & 0.000 & $-0.008 *$ & 0.011 & $-0.014 * *$ & 0.000 \\
\hline Man. PCCM / Vol. HMO & -0.007 & 0.099 & $-0.011 * *$ & 0.000 & -0.007 & 0.162 & $-0.007 *$ & 0.023 \\
\hline Voluntary PCCM/HMO & $-0.013^{*}$ & 0.012 & $-0.010 * *$ & 0.009 & $-0.013^{*}$ & 0.021 & -0.005 & 0.106 \\
\hline Voluntary - HMO & 0.002 & 0.474 & 0.001 & 0.791 & 0.005 & 0.150 & 0.003 & 0.095 \\
\hline Voluntary - PCCM & $-0.011^{*}$ & 0.048 & -0.005 & 0.162 & -0.009 & 0.138 & -0.001 & 0.794 \\
\hline Low Birth Weight & $\mu=0.085$ & & $\mu=0.068$ & & $\mu=0.067$ & & $\mu=0.041$ & \\
\hline Mandatory PCCM/HMO & $0.020 * *$ & 0.000 & $0.017 * *$ & 0.000 & $0.017 * *$ & 0.000 & $0.010^{* *}$ & 0.000 \\
\hline Mandatory - HMO & $0.012^{* *}$ & 0.000 & $0.012 * *$ & 0.000 & $0.013^{* *}$ & 0.000 & $0.006^{* *}$ & 0.000 \\
\hline Mandatory - PCCM & $0.014 * *$ & 0.000 & $0.008^{* *}$ & 0.000 & $0.008^{* *}$ & 0.000 & $0.005^{* *}$ & 0.000 \\
\hline Man. PCCM / Vol. HMO & $0.011^{* *}$ & 0.000 & $0.014^{* *}$ & 0.000 & $0.011^{* *}$ & 0.000 & $0.007 * *$ & 0.000 \\
\hline Voluntary PCCM/HMO & $0.012 * *$ & 0.000 & $0.009 * *$ & 0.000 & 0.005 & 0.065 & $0.005 * *$ & 0.002 \\
\hline Voluntary - HMO & $0.004 *$ & 0.015 & $0.005^{* *}$ & 0.000 & $0.005^{* *}$ & 0.007 & $0.002 *$ & 0.016 \\
\hline Voluntary - PCCM & 0.006 & 0.072 & $0.006^{* *}$ & 0.005 & -0.000 & 0.896 & 0.002 & 0.229 \\
\hline Preterm Birth & $\mu=0.118$ & & $\mu=0.102$ & & $\mu=0.097$ & & $\mu=0.073$ & \\
\hline Mandatory PCCM/HMO & $0.028^{* *}$ & 0.000 & $0.032 * *$ & 0.000 & $0.031 * *$ & 0.000 & $0.019 * *$ & 0.000 \\
\hline Mandatory - HMO & $0.025^{* *}$ & 0.000 & $0.021^{* *}$ & 0.000 & $0.025^{* *}$ & 0.000 & $0.013^{* *}$ & 0.000 \\
\hline Mandatory - PCCM & $0.018^{* *}$ & 0.000 & $0.014^{* *}$ & 0.000 & $0.016^{* *}$ & 0.000 & $0.009 * *$ & 0.000 \\
\hline Man. PCCM / Vol. HMO & $0.022 * *$ & 0.000 & $0.024 * *$ & 0.000 & $0.019^{* *}$ & 0.000 & $0.011 * *$ & 0.000 \\
\hline Voluntary PCCM/HMO & $0.016^{* *}$ & 0.000 & $0.016^{* *}$ & 0.000 & $0.010^{* *}$ & 0.006 & $0.008^{* *}$ & 0.000 \\
\hline Voluntary - HMO & $0.010 * *$ & 0.000 & $0.012 * *$ & 0.000 & $0.007^{* *}$ & 0.000 & $0.005^{* *}$ & 0.000 \\
\hline Voluntary - PCCM & 0.005 & 0.173 & $0.007^{* *}$ & 0.005 & 0.004 & 0.291 & 0.003 & 0.235 \\
\hline Cesarean Section & $\mu=0.137$ & & $\mu=0.164$ & & $\mu=0.133$ & & $\mu=0.159$ & \\
\hline Mandatory PCCM/HMO & -0.002 & 0.700 & 0.000 & 0.914 & 0.000 & 0.948 & 0.003 & 0.490 \\
\hline Mandatory - HMO & 0.003 & 0.392 & $0.006^{*}$ & 0.018 & 0.004 & 0.273 & 0.001 & 0.799 \\
\hline Mandatory - PCCM & -0.002 & 0.333 & 0.000 & 0.932 & 0.003 & 0.222 & -0.001 & 0.723 \\
\hline Man. PCCM / Vol. HMO & -0.001 & 0.782 & -0.002 & 0.507 & 0.006 & 0.089 & 0.004 & 0.159 \\
\hline Voluntary PCCM/HMO & 0.004 & 0.268 & -0.002 & 0.606 & 0.000 & 0.998 & -0.000 & 0.873 \\
\hline Voluntary - HMO & 0.002 & 0.439 & 0.001 & 0.420 & -0.002 & 0.571 & -0.001 & 0.738 \\
\hline Voluntary - PCCM & 0.000 & 0.966 & -0.002 & 0.537 & -0.001 & 0.792 & 0.002 & 0.534 \\
\hline Num. of Observations & $1,134,473$ & & $1,835,800$ & & $1,143,919$ & & $1,985,594$ & \\
\hline
\end{tabular}


Notes: Estimates were obtained using ordinary least squares regression. All regression models include the following variables: county fixed effects, mother's age (8 dummy variables), a dummy variable indicating that mother was foreign born, a dummy variable indicating first birth, year (6 dummy variables), and state-specific linear trend. The number of observations listed in the table refers to the analysis of the number of prenatal care visits. For other outcomes, the sample size may be slightly larger or smaller. Due to the large size of the population of white, married women with 12 to 15 years of education, a 25 percent sample was used in the analysis. 
Table A5. Estimates of the Effect of Medicaid Managed Care on Maternal and Infant Health non-Hispanic, Black Women, 1990-1996

\begin{tabular}{|c|c|c|c|c|c|c|c|c|}
\hline \multirow[b]{2}{*}{ Outcome } & \multicolumn{2}{|c|}{$<12$, Unmarried } & \multicolumn{2}{|c|}{ 12-15, Unmarried } & \multicolumn{2}{|c|}{$<12$, Married } & \multicolumn{2}{|c|}{ 12-15, Married } \\
\hline & $\beta$ & $\mathrm{p}$-Value & $\beta$ & $\mathrm{p}$-Value & $\beta$ & p-Value & $\beta$ & p-Value \\
\hline Num. Prenatal Visits & $\mu=8.8$ & & $\mu=10.0$ & & $\mu=9.7$ & & $\mu=11.3$ & \\
\hline Mandatory PCCM/HMO & $-0.291 * *$ & 0.000 & $-0.393 * *$ & 0.000 & $-0.467 *$ & 0.028 & $-0.315^{* *}$ & 0.000 \\
\hline Mandatory - HMO & $-0.386^{* *}$ & 0.000 & $-0.438 * *$ & 0.000 & $-0.431 *$ & 0.017 & $-0.248 * *$ & 0.000 \\
\hline Mandatory - PCCM & $-0.178 * *$ & 0.000 & $-0.169 * *$ & 0.000 & -0.094 & 0.337 & $-0.087 * *$ & 0.006 \\
\hline Man. PCCM / Vol. HMO & $-0.216^{* *}$ & 0.000 & $-0.211 * *$ & 0.000 & -0.136 & 0.273 & -0.064 & 0.128 \\
\hline Voluntary PCCM/HMO & $0.345^{* *}$ & 0.000 & $0.200^{* *}$ & 0.000 & $0.314^{*}$ & 0.037 & $0.272 * *$ & 0.000 \\
\hline Voluntary - HMO & $-0.149 * *$ & 0.000 & $-0.165 * *$ & 0.000 & -0.147 & 0.118 & $-0.092 * *$ & 0.004 \\
\hline Voluntary - PCCM & 0.032 & 0.610 & $0.100^{*}$ & 0.012 & 0.213 & 0.166 & 0.082 & 0.106 \\
\hline $\begin{array}{l}\text { Inadequate Prenatal Care } \\
\text { (APNCU) }\end{array}$ & $\mu=0.53$ & & $\mu=0.42$ & & $\mu=0.45$ & & $\mu=0.28$ & \\
\hline Mandatory PCCM/HMO & -0.016 & 0.054 & $-0.015^{*}$ & 0.020 & 0.019 & 0.401 & $-0.018^{*}$ & 0.029 \\
\hline Mandatory - HMO & $0.012 *$ & 0.049 & $0.010^{*}$ & 0.031 & 0.013 & 0.518 & 0.005 & 0.362 \\
\hline Mandatory - PCCM & 0.000 & 0.868 & -0.004 & 0.174 & -0.019 & 0.072 & $-0.105^{* *}$ & 0.002 \\
\hline Man. PCCM / Vol. HMO & $-0.020 * *$ & 0.000 & $-0.021 * *$ & 0.000 & 0.000 & 0.996 & $-0.020 * *$ & 0.000 \\
\hline Voluntary PCCM/HMO & $-0.045 * *$ & 0.000 & $-0.026 * *$ & 0.000 & -0.014 & 0.392 & $-0.025^{* *}$ & 0.000 \\
\hline Voluntary - HMO & -0.000 & 0.953 & $-0.003 * *$ & 0.359 & 0.003 & 0.739 & -0.006 & 0.074 \\
\hline Voluntary - PCCM & $-0.026 * *$ & 0.000 & $-0.019 * *$ & 0.000 & -0.004 & 0.807 & -0.008 & 0.140 \\
\hline Low Birth Weight & $\mu=0.140$ & & $\mu=0.122$ & & $\mu=0.121$ & & $\mu=0.093$ & \\
\hline Mandatory PCCM/HMO & $0.042^{* *}$ & 0.000 & $0.051^{* *}$ & 0.000 & $0.055^{* *}$ & 0.000 & $0.046 * *$ & 0.000 \\
\hline Mandatory - HMO & $0.025^{* *}$ & 0.000 & $0.031 * *$ & 0.000 & 0.020 & 0.119 & $0.018^{* *}$ & 0.000 \\
\hline Mandatory - PCCM & $0.012^{* *}$ & 0.000 & $0.018^{* *}$ & 0.000 & $0.022 * *$ & 0.002 & $0.014 * *$ & 0.000 \\
\hline Man. PCCM / Vol. HMO & $0.030^{* *}$ & 0.000 & $0.030^{* *}$ & 0.000 & $0.023 * *$ & 0.007 & $0.025^{* *}$ & 0.000 \\
\hline Voluntary PCCM/HMO & $0.014^{* *}$ & 0.000 & $0.019^{* *}$ & 0.000 & -0.005 & 0.652 & $0.012 * *$ & 0.000 \\
\hline Voluntary - HMO & $0.008^{* *}$ & 0.002 & $0.012 * *$ & 0.000 & 0.006 & 0.387 & $0.008^{* *}$ & 0.000 \\
\hline Voluntary - PCCM & 0.009 & 0.059 & $0.009 * *$ & 0.001 & 0.011 & 0.326 & 0.001 & 0.872 \\
\hline Preterm Birth & $\mu=0.204$ & & $\mu=0.175$ & & $\mu=0.174$ & & $\mu=0.140$ & \\
\hline Mandatory PCCM/HMO & $0.074 * *$ & 0.000 & $0.079 * *$ & 0.000 & $0.108^{* *}$ & 0.000 & $0.065^{* *}$ & 0.000 \\
\hline Mandatory - HMO & $0.048^{* *}$ & 0.000 & $0.042 * *$ & 0.000 & $0.034^{*}$ & 0.039 & $0.023 * *$ & 0.000 \\
\hline Mandatory - PCCM & $0.021^{* *}$ & 0.000 & $0.024^{* *}$ & 0.000 & $0.021^{* *}$ & 0.008 & $0.019^{* *}$ & 0.000 \\
\hline Man. PCCM / Vol. HMO & $0.042 * *$ & 0.000 & $0.049 * *$ & 0.002 & $0.029 * *$ & 0.003 & $0.038 * *$ & 0.003 \\
\hline Voluntary PCCM/HMO & $0.013^{* *}$ & 0.004 & $0.018^{* *}$ & 0.000 & -0.001 & 0.949 & $0.015^{* *}$ & 0.000 \\
\hline Voluntary - HMO & $0.014 * *$ & 0.000 & $0.017^{* *}$ & 0.000 & 0.006 & 0.420 & $0.009 * *$ & 0.000 \\
\hline Voluntary - PCCM & 0.001 & 0.925 & 0.000 & 0.923 & 0.005 & 0.704 & 0.002 & 0.691 \\
\hline Cesarean Section & $\mu=0.131$ & & $\mu=0.157$ & & $\mu=0.134$ & & $\mu=0.170$ & \\
\hline Mandatory PCCM/HMO & -0.002 & 0.728 & -0.004 & 0.361 & 0.013 & 0.386 & -0.005 & 0.429 \\
\hline Mandatory - HMO & $0.018^{* *}$ & 0.000 & $0.014^{* *}$ & 0.000 & -0.001 & 0.959 & $0.010^{*}$ & 0.041 \\
\hline Mandatory - PCCM & 0.001 & 0.751 & -0.000 & 0.997 & 0.010 & 0.157 & 0.005 & 0.108 \\
\hline Man. PCCM / Vol. HMO & $0.009 * *$ & 0.003 & -0.003 & 0.285 & -0.002 & 0.845 & -0.001 & 0.722 \\
\hline Voluntary PCCM/HMO & 0.006 & 0.115 & -0.002 & 0.506 & -0.006 & 0.605 & -0.002 & 0.707 \\
\hline Voluntary - HMO & 0.004 & 0.084 & -0.002 & 0.269 & 0.005 & 0.431 & -0.003 & 0.315 \\
\hline Voluntary - PCCM & -0.002 & 0.704 & -0.005 & 0.107 & -0.007 & 0.525 & -0.001 & 0.861 \\
\hline Num. of Observations & $1,040,518$ & & $1,617,698$ & & 133,243 & & 872,744 & \\
\hline
\end{tabular}

Notes: Estimates were obtained using ordinary least squares regression. All regression models include the following variables: county fixed effects, mother's age (8 dummy variables), a dummy variable indicating that mother was foreign born, a dummy 
variable indicating first birth, year (6 dummy variables), and state-specific linear trend. The number of observations listed in the table refers to the analysis of the number of prenatal care visits. For other outcomes, the sample size may be slightly larger or smaller. Due to the large size of the population of white, married women with 12 to 15 years of education, a 25 percent sample was used in the analysis. 
Table A6. Estimates of the Effect of Medicaid Managed Care on Maternal and Infant Health Hispanic (any race) Women, 1990-1996

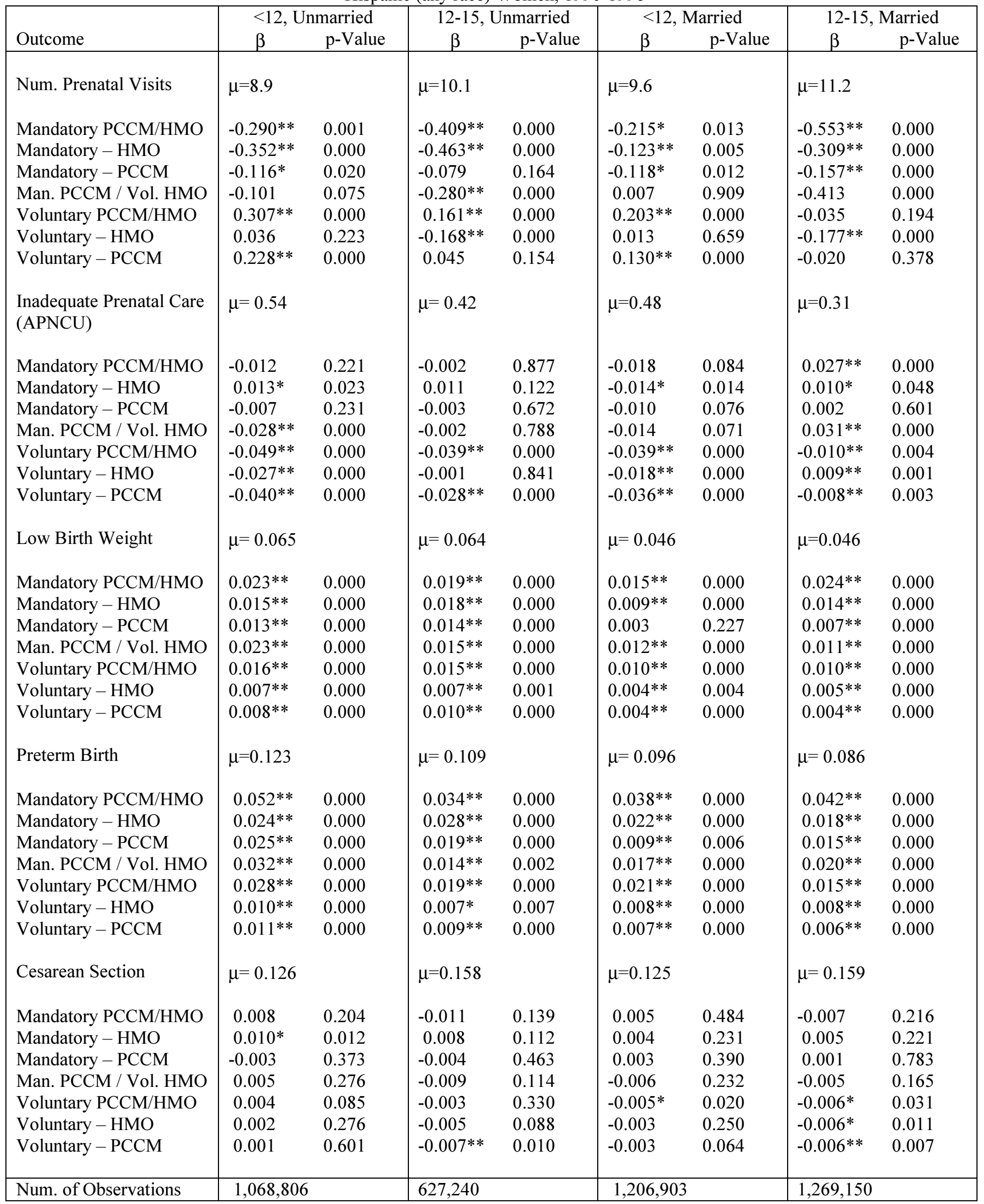

Notes: Estimates were obtained using ordinary least squares regression. All regression models include the following variables: county fixed effects, mother's age (8 dummy variables), a dummy variable indicating that mother was foreign born, a dummy 
variable indicating first birth, year (6 dummy variables), and state-specific linear trend. The number of observations listed in the table refers to the analysis of the number of prenatal care visits. For other outcomes, the sample size may be slightly larger or smaller. Due to the large size of the population of white, married women with 12 to 15 years of education, a 25 percent sample was used in the analysis. 